\title{
Host insulin stimulates Echinococcus multilocularis insulin signalling pathways and larval development
}

Sarah Hemer ${ }^{1 \dagger}$, Christian Konrad ${ }^{1 \dagger}$, Markus Spiliotis ${ }^{1}$, Uriel Koziol $^{1}$, Dominik Schaack ${ }^{2}$, Sabine Förster ${ }^{1}$, Verena Gelmedin', Britta Stadelmann ${ }^{3}$, Thomas Dandekar², Andrew Hemphill ${ }^{3}$ and Klaus Brehm ${ }^{1 *}$

\begin{abstract}
Background: The metacestode of the tapeworm Echinococcus multilocularis is the causative agent of alveolar echinococcosis, a lethal zoonosis. Infections are initiated through establishment of parasite larvae within the intermediate host's liver, where high concentrations of insulin are present, followed by tumour-like growth of the metacestode in host organs. The molecular mechanisms determining the organ tropism of E. multilocularis or the influences of host hormones on parasite proliferation are poorly understood.

Results: Using in vitro cultivation systems for parasite larvae we show that physiological concentrations (10 nM) of human insulin significantly stimulate the formation of metacestode larvae from parasite stem cells and promote asexual growth of the metacestode. Addition of human insulin to parasite larvae led to increased glucose uptake and enhanced phosphorylation of Echinococcus insulin signalling components, including an insulin receptor-like kinase, EmIR1, for which we demonstrate predominant expression in the parasite's glycogen storage cells. We also characterized a second insulin receptor family member, EmIR2, and demonstrated interaction of its ligand binding domain with human insulin in the yeast two-hybrid system. Addition of an insulin receptor inhibitor resulted in metacestode killing, prevented metacestode development from parasite stem cells, and impaired the activation of insulin signalling pathways through host insulin.

Conclusions: Our data indicate that host insulin acts as a stimulant for parasite development within the host liver and that E. multilocularis senses the host hormone through an evolutionarily conserved insulin signalling pathway. Hormonal host-parasite cross-communication, facilitated by the relatively close phylogenetic relationship between E. multilocularis and its mammalian hosts, thus appears to be important in the pathology of alveolar echinococcosis. This contributes to a closer understanding of organ tropism and parasite persistence in larval cestode infections. Furthermore, our data show that Echinococcus insulin signalling pathways are promising targets for the development of novel drugs.
\end{abstract}

Keywords: Cestode, Tapeworm, Echinococcus, Echinococcosis, Insulin, Receptor kinase, Kinase inhibitor, Host-parasite interaction

\footnotetext{
* Correspondence: kbrehm@hygiene.uni-wuerzburg.de

${ }^{\dagger}$ Equal contributors

${ }^{1}$ University of Würzburg, Institute of Hygiene and Microbiology, Josef-Schneider-Strasse 2, D-97080 Würzburg, Germany

Full list of author information is available at the end of the article
} 


\section{Background}

The metacestode stage of the fox-tapeworm Echinococcus multilocularis is the causative agent of alveolar echinococcosis (AE), one of the most serious parasitic diseases in the Northern Hemisphere [1]. Initial infection of the intermediate host (rodents, humans) occurs through oral uptake of infectious eggs that contain the oncosphere. Upon hatching from the egg within the intermediate host's intestine, the oncosphere penetrates the intestinal wall and gains access to the inner organs. Almost exclusively within the liver, the oncosphere then undergoes a metamorphic transition towards the metacestode that is driven by parasite stem cells [2]. Once formed as small cystic structures, the metacestode tissue proliferates and infiltrates host tissue like a malignant tumour, eventually giving rise to numerous protoscoleces that either develop into the strobilar adult stage, when transmitted to the definitive host, or 're-differentiate' towards the metacestode, when distributed in the intermediate host see Additional file 1 [1-3].

All larval developmental transitions of E. multilocularis as well as proliferation of metacestode tissue take place in close contact with the intermediate host's endocrine and paracrine systems, which involve numerous evolutionarily conserved hormones, such as insulin or cytokines of the epidermal growth factor (EGF) and the transforming growth factor- $\beta$ (TGF- $\beta$ ) families. Since the parasite expresses respective surface receptor kinases it has already been suggested that the host-parasite interplay in AE might rely on hormonal host-parasite cross communication [2], although little information on the underlying interaction mechanisms is currently available. Of particular interest in the case of E. multilocularis are possible effects of host-derived insulin since, in mammalian hosts, the highest concentrations of this hormone can be found at the junction between the portal vein and the liver parenchyma [4-6], which is also the liver entry site of the oncosphere [2].

Due to its important role in regulating a variety of metabolic and developmental processes, insulin signalling has been well studied in mammals and invertebrate model systems, such as Caenorhabditis elegans and Drosophila melanogaster [7-9]. Insulin signalling is initiated by binding of insulin-like hormones to surface receptor tyrosine kinases of the insulin/insulin-like growth factor (IGF) family that are usually produced as long pro-peptides which are later processed into an extracellular $\alpha$-subunit and a membrane-spanning $\beta$ subunit, connected by a disulphide bridge [7-9]. Upon ligand binding to surface associated $\alpha 2 \beta 2$ receptor tetramers, auto-phosphorylation of several tyrosine residues within the $\beta$-subunit is induced, one of which forms part of a well conserved NPXY-motif that is located in the juxta-membrane region [7-9]. Downstream signalling is then induced by binding of intracellular adapter proteins (for example, insulin receptor substrate; IRS) to the phosphorylated NPXY motif. The two major downstream signalling pathways in vertebrates and invertebrates are the ERK1/2 mitogen-activated protein kinase (MAPK) cascade and the phosphoinositide-3-kinase (PI3K)/protein kinase $B$ (PKB; also known as Akt) pathway [7-9].

Insulin signalling mechanisms have already been studied to a certain extent in parasitic and free-living flatworms. Tyrosine kinases of the insulin receptor family have been fully characterized in the cestode $E$. multilocularis [10] and the trematodes Schistosoma mansoni [11,12] and S. japonicum [13]. Using the yeast two-hybrid system it was further shown that the ligand binding domains (LBD) of the flatworm insulin receptor tyrosine kinases are principally able to bind human insulin $[10,11,13]$, although it is not yet clear whether they are also activated by insulin when expressed at the parasite surface. Reduced glucose uptake in in vitro cultivated schistosomes upon treatment with insulin receptor inhibitors indicated that, at least in trematodes, insulin signalling might regulate glucose homeostasis [12]. Several investigations on the direct influence of host insulin on flatworm parasite glucose uptake and/or development showed slight effects and were carried out using un-physiologically high concentrations of the host hormone $[12,14,15]$. Finally, a very recent study in the free-living model system Schmidtea mediterranea demonstrated a role of insulin signalling in the regulation of flatworm stem cell activity and proliferation [16].

During recent years, we have developed several cultivation systems by which the developmental transitions of E. multilocularis larvae within the intermediate host can be mimicked in vitro [2,17-19]. These include systems for investigating proliferation and differentiation of metacestode vesicles under host cell free conditions [18] as well as a parasite stem cell cultivation system that closely mimics the metamorphic transition of the oncosphere towards the metacestode $[19,20]$. Using these systems we addressed, in the present study, questions on the influence of physiological concentrations of human insulin on parasite development, glucose uptake and the activation of Echinococcus insulin signalling pathways. We demonstrate that E. multilocularis larval development is significantly stimulated in the presence of physiological concentrations of human insulin, and that the parasite's insulin signalling pathways are activated upon exogenous addition of insulin. We also show that the E. multilocularis insulin signalling pathways are affected by an insulin receptor inhibitor originally designed against the human insulin receptor and that this treatment results in impaired larval development and parasite killing. 


\section{Results}

Host insulin stimulates E. multilocularis larval development in vitro

To study the influence of human insulin on parasite development, three different in vitro cultivation systems were used. First, we studied the effect of insulin on isolated E. multilocularis primary cells that contain high numbers of totipotent stem cells, which lead to the formation of metacestode vesicles in a manner that closely resembles the oncosphere-metacestode transition during the early phase of in vivo infections $[19,20]$. As depicted in Figure 1A, parasite cell aggregates that result from stem cell proliferation [19] were always larger in insulin treated samples and, when compared to the control, also contained larger internal cavities which later gave rise to mature vesicles. The formation of mature vesicles was also significantly stimulated and approximately threefold and six-fold more vesicles were detected after one week incubation in the presence of $10 \mathrm{nM}$ and $100 \mathrm{nM}$ insulin, respectively (Figure 1B). Although insulintreated samples consistently yielded higher numbers of mature metacestode vesicles, the eventually obtained vesicle size in these samples was not significantly enlarged when compared to the controls (data not shown). As displayed in Figure 1C, insulin-treatment also significantly stimulated the uptake of bromodeoxyuridine (BrdU) in parasite primary cell cultures, indicating that the host hormone has a direct effect on the proliferation rate of parasite stem cells, which are the only cells capable of proliferation in flatworms [2].

We next tested the effects of host insulin on the development of mature metacestode vesicles. Although insulin-treatment showed a clear trend to yield larger vesicles after about two weeks of incubation (data not shown), measurement of parasite development on the basis of vesicle volume increase is difficult in this system. We, therefore, mainly tested stem cell proliferation and, as shown in Figure 1D, insulin treatment significantly stimulated BrdU uptake in metacestode vesicles, although not as prominently as in the case of primary stem cell cultures.

Protoscoleces of the closely related dog-tapeworm $E$. granulosus show the unique capacity of being able to mature into strobilar adult stages, when ingested by a definitive canid host, but also of 're-differentiating' into fully developed cysts when released into the intermediate host body cavity upon cyst rupture [3]. This capacity appears to be also shared by protoscoleces of E. multilocularis [21]. To investigate the effects of host insulin on the Echinococcus re-differentiation processes, we employed a cultivation system in which $E$. multilocularis protoscoleces were kept in the presence of hepatocyteconditioned medium that usually induces vesicle formation from parasite stem cells [19]. As shown in Figure 1E, E. multilocularis protoscoleces did indeed re-differentiate into fully mature metacestode vesicles under these conditions, although the number of protoscoleces that underwent re-differentiation was usually very low (about $2.2 \%$ of all protoscoleces in culture). In the presence of $1 \mathrm{nM}$ or 10 $\mathrm{nM}$ insulin, however, the number of fully re-differentiated protoscoleces was significantly increased by around $50 \%$ (Figure 1F).

Taken together, these results indicated that E. multilocularis stem cell cultures and larvae are responsive to physiologically relevant concentrations of host insulin and that this treatment stimulates the formation of metacestode vesicles either from stem cell cultures or from protoscoleces.

\section{Characterization of $E$. multilocularis insulin-receptors}

We had previously characterized an insulin-like receptor tyrosine kinase of E. multilocularis, originally designated EmIR, which at least in the yeast two-hybrid system interacted with human pro-insulin [10]. When analysing the recently released whole genome sequence of $E$. $m u l$ tilocularis [22] the respective gene, emir, was identified on scaffold 7780 (gene ID: EmuJ_000962900) and comprised 25 exons, separated by 24 introns, as previously determined [10]. In extensive Basic Local Alignment Search Tool (BLAST) analyses using the amino acid sequences of the human insulin receptor (HIR), EmIR, and previously described insulin receptors from schistosomes [11-13], we found a second gene on the E. multilocularis genome that obviously encoded another receptor tyrosine kinase of the insulin receptor family. The respective gene was designated emir2 (scaffold 7780; gene ID: EmuJ_000981300; 24 exons) and the previously identified gene, emir, was re-named to emir1. The entire emir2 cDNA was cloned and sequenced and found to encode a protein, EmIR2, of 1,671 amino acids (181 kDa). In Simple Modular Architecture Research Tool (SMART) homology analyses, EmIR2 displayed a domain structure typical of insulin receptor tyrosine kinases, with a predicted signal peptide, a LBD composed of two receptor L domains separated by a furin domain, three fibronectin 3 domains, a transmembrane domain and an intracellular tyrosine kinase domain (TKD) (Figure 2). Particularly within the TKD and the LBD, EmIR2 showed significant amino acid sequence homologies to EmIR1 and insulin receptors of mammalian and schistosome origin [see Additional file 2]. Interestingly, and in contrast to EmIR1, EmIR2 did not contain a NPXY motif in the juxtamembrane region which, in HIR, is important for downstream signalling through IRS [7-9] (Figure 2).

We considered both EmIR1 and EmIR2 likely candidates for mediating the effects of host insulin on the parasite larval stages and, thus, analysed the role of these 


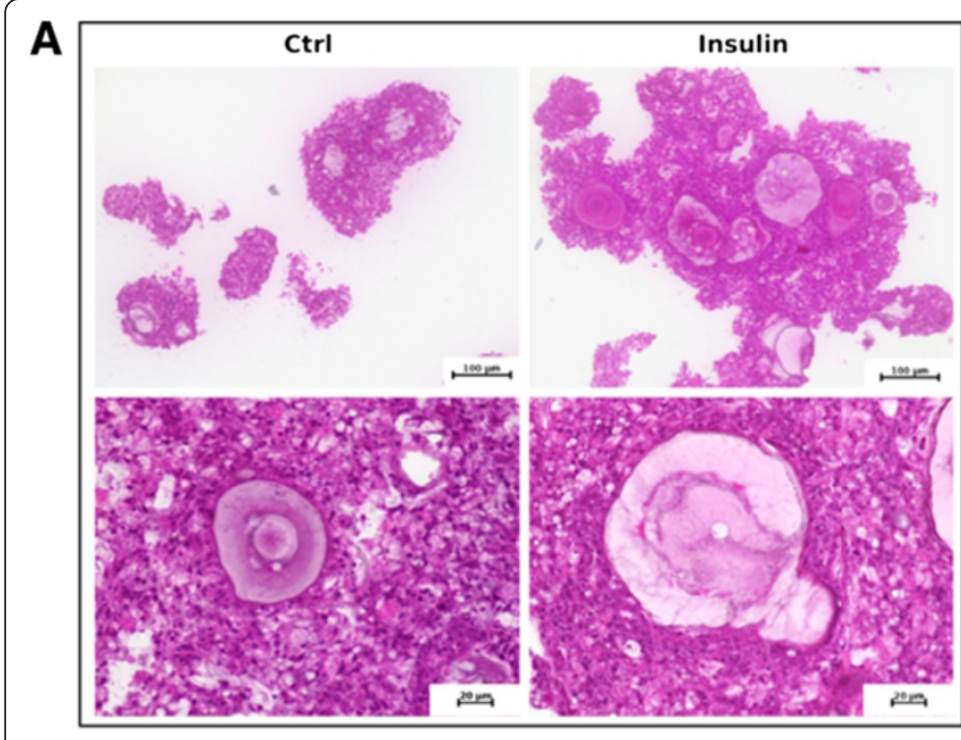

B

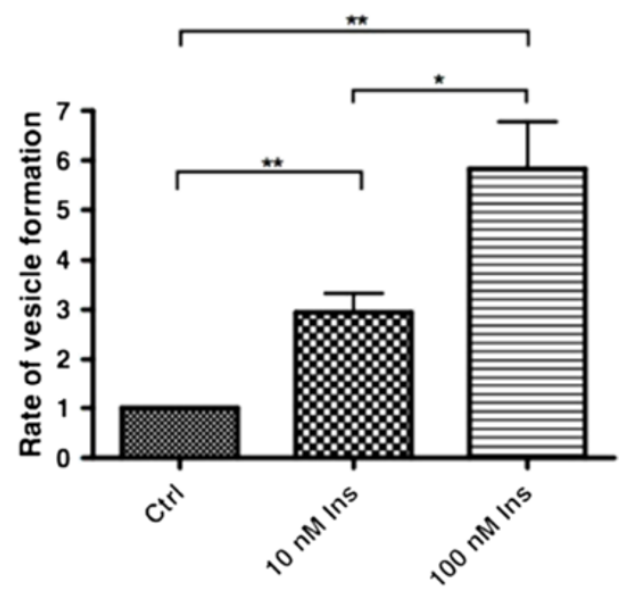

C

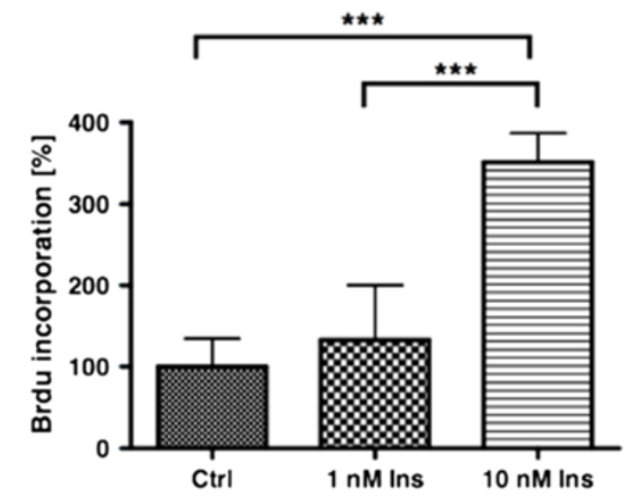

D

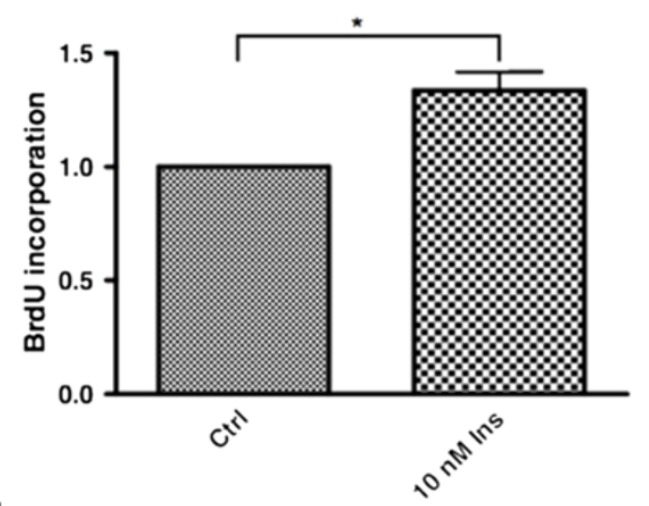

E

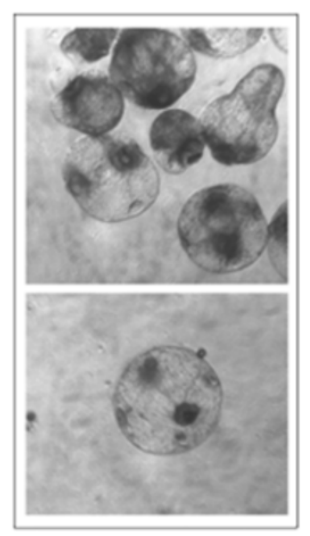

$\mathbf{F}$

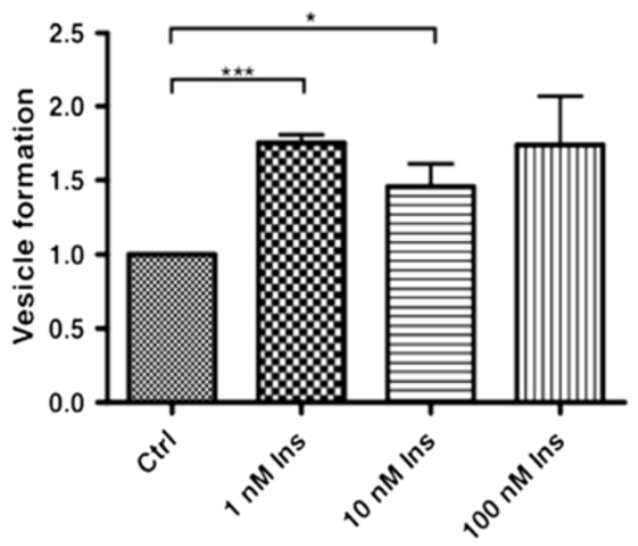

Figure 1 (See legend on next page.) 
(See figure on previous page.)

Figure 1 Effects of insulin on E. multilocularis larval development. A) Morphology of primary cell aggregates. Primary cells were isolated from axenic metacestode vesicles and cultivated in 2\% FCS/(D)MEM supplemented with or without $10 \mathrm{nM}$ human insulin for one week. The aggregates were fixed and embedded in Technovit 8100. Sections $(4 \mu \mathrm{m})$ were stained with haematoxylin/eosin. B) Formation of metacestode vesicles. Primary cells were cultivated in conditioned medium supplemented with human insulin for three weeks and mature metacestode vesicles were counted. Control was set to 1 and results were normalised against the control. $\left(^{*}\right) P$ values below $0.05,\left(^{* *}\right)$ very significant for $P$ between 0.001 and $\left.0.01,{ }^{* * *}\right)$ extremely significant for $P<0.001$. C) BrdU uptake by parasite cell cultures. Primary cells were isolated and incubated for 24 hours with insulin. BrdU was added for four hours and BrdU uptake was measured with the colorimetric BrdU ELISA kit (Roche, Mannheim, Germany). Asterisks mark significant values. D) BrdU uptake by mature metacestode vesicles. Metacestode vesicles were incubated for two days in the presence or absence of insulin and BrdU. BrdU uptake was measured after chromosomal DNA isolation with the colorimetric BrdU ELISA kit (Roche). E) Re-differentiation and microcyst formation of E. multilocularis protoscoleces. Examples of microcysts forming in in vitro protoscolex cultures. F) Microcyst formation of in vitro cultivated protoscoleces incubated with insulin for three weeks. Control was set to 1 and results were normalised against the control. $\left(^{*}\right) P$ values below $0.05,\left(^{*}\right)$ very significant for $P$ between 0.001 and $0.01,\left({ }^{* *}\right)$ extremely significant for $P<0.001$. BrdU, bromodeoxyuridine.

kinases in Echinococcus insulin signalling in more detail. First, we carried out semi-quantitative RT-PCR experiments to analyse the expression patterns of the Echinococcus insulin receptor genes in different larval stages. As shown in Figure 3A, emir1 and emir2 expression was detected in all larval stages that were responsive to host insulin. We also analysed the expression levels of both genes in available transcriptome data sets that were generated for gene annotation of the E. multilocularis genome project [22]. According to these data, emir1 is about two- to three-fold higher expressed in Echinococcus larvae than emir2, and both genes show the lowest expression levels in adult worms [see Additional file 3]. For biochemical and histochemical investigations, we next produced specific antisera directed against the intracellular portions of EmIR1 and EmIR2 [see Additional file 4]. As shown in Figure 3B, the anti-EmIR1 antiserum detected a band of approximately $150 \mathrm{kDa}$, the intensity of which increased upon treatment of parasite lysate with $\beta$-mercaptoethanol, as well as several larger bands around $195 \mathrm{kDa}$. This pattern indicated that the $150 \mathrm{kDa}$ band represents the EmIR1 $\beta$-subunit, whereas the $195 \mathrm{kDa}$ band(s) are most likely $\alpha \beta$-subunit dimers that are still connected by disulphide bridges. The actual molecular mass of the EmIR1 $\beta$-subunit is higher than the calculated mass of the polypeptide (approximately $100 \mathrm{kDa}$ ), which is most probably due to post-translational modification, such as glycosylation, as has already been shown for insulin receptor $\beta$-subunits of other organisms, including the human insulin receptor [23]. In the case of EmIR2, an intense band of $87 \mathrm{kDa}$ was observed when immunoprecipitates were treated with $10 \% \beta$-mercaptoethanol, indicating that this is the EmIR2 $\beta$-subunit, whereas in the presence of $1 \%$ $\beta$-mercaptoethanol one large band was visible that, due to its size of $>230 \mathrm{kDa}$, could represent an $\alpha 2 \beta 2$ tetramer. When total parasite lysate was probed with the anti-EmIR2 antiserum, a smaller band of approximately $60 \mathrm{kDa}$ was detected alongside the $87 \mathrm{kDa}$ band, which could be due to alternative processing of the EmIR2 $\beta$ subunit (Figure 3D).

Interestingly, when we analysed the E. multilocularis larval stages for the presence of EmIR1 in Western blot experiments, clear signals were obtained for protoscoleces and metacestode vesicles but no signal was obtained for primary cell cultures (Figure 3D). In the case of EmIR2, on the other hand, signals were obtained for protoscoleces and primary cells, but only a very faint signal was seen in metacestode preparations (Figure 3D). Since RT-PCR and transcriptome data revealed the presence of emirl transcripts in primary cell cultures and emir2 transcripts in metacestode vesicles (see above),

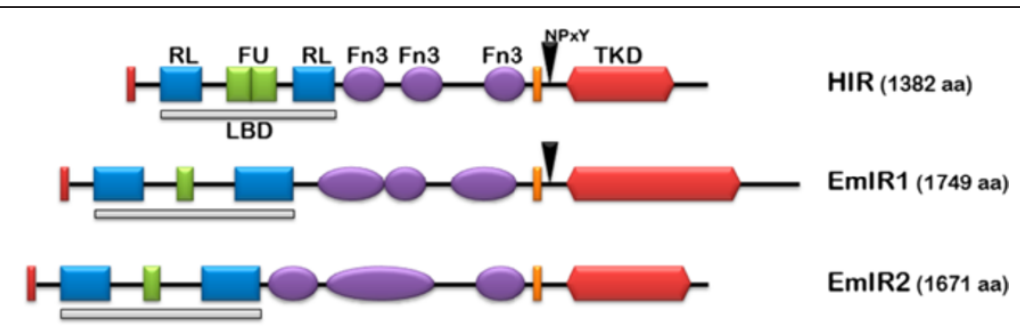

Figure 2 Domain structure of E. multilocularis insulin receptors. Schematic representation of the domain structures of the human insulin receptor (HIR), EmIR1 and EmIR2 according to SMART analyses (Letunic et al., 2012). Displayed are the location and size of the following predicted domains: TKD, tyrosine kinase domain; LBD, ligand binding domain; RL, receptor-L-domain; FU, furin-rich repeat; Fn3, fibronectin 3 domain. The presence of NPXY-motifs for binding of IRS is indicated by an arrowhead. Red bars at the N-terminus represent signal peptides, orange bars represent transmembrane domains. IRS, insulin receptor substrate; SMART, Simple Modular Architecture Research Tool. 


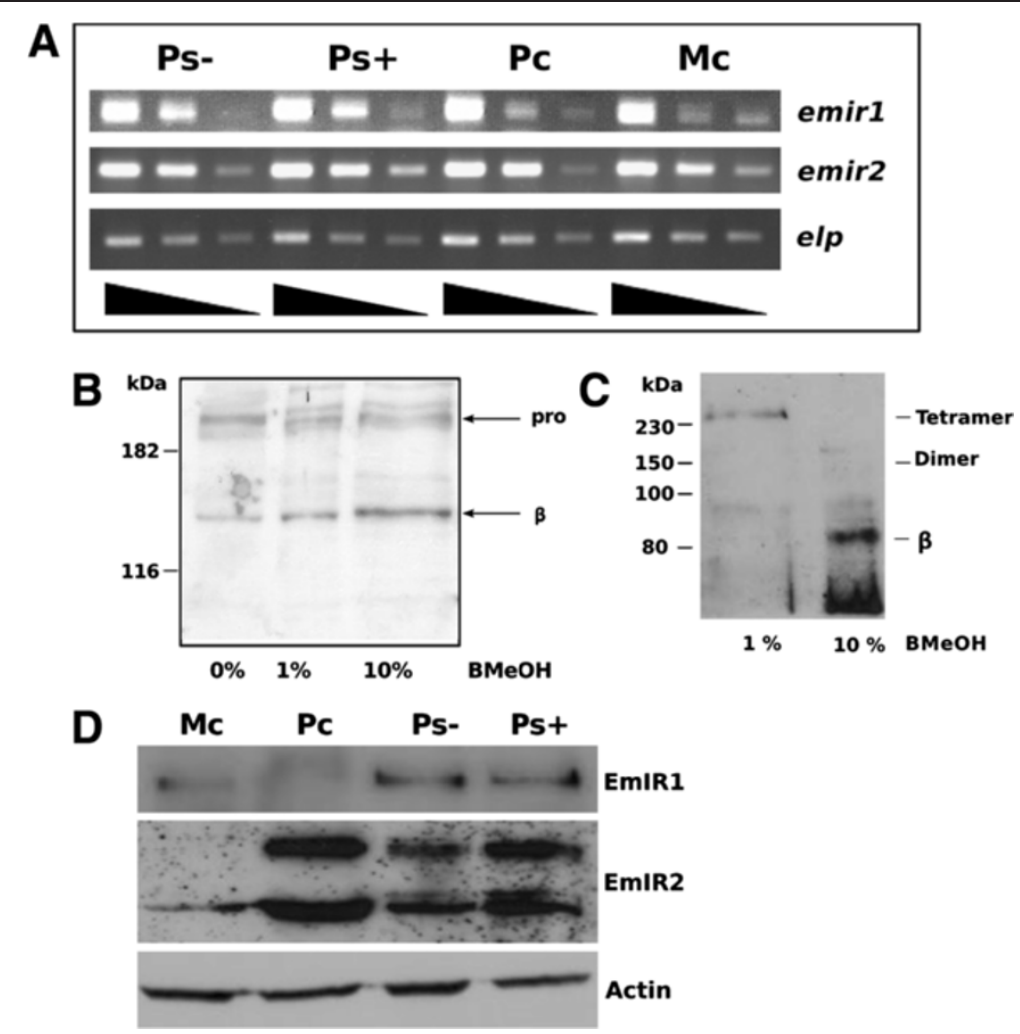

Figure 3 Expression of EmIR1 and EmIR2 in E. multilocularis larval stages. A) Semi-quantitative RT-PCR of emir1 and emir2 expression. Serial $1 / 10$ dilutions of cDNA from metacestode vesicles (MC), primary cells (PC) as well as dormant (PS-) and low pH/pepsin-activated protoscoleces (PS+) were subjected to gene-specific PCR using intron-flanking primers. PCR products were separated on a $1 \%$ agarose gel and stained with ethidium bromide. The constitutively expressed gene elp was used as control. B) Western blot and immunoprecipitation employing the EmIR1 anti-serum. EmIR1 was immunoprecipitated from metacestode vesicles and treated with $\beta$-mercaptoethanol (beta-MeOH) at concentrations of $0 \%, 1 \%$ and $10 \%$. Probes were then separated on a $12.5 \%$ polyacrylamide gel and developed using the anti-EmIR1 antiserum. 'pro' and 'beta' indicate the pro-form and the $\beta$-subunit of EmIR, respectively. C) Immunoprecipitation and Western blot using the anti-EmIR2 serum. EmIR2 was immunoprecipitated from protoscolex preparations, samples were then supplemented with $1 \%$ or $10 \%$ of $\beta$-mercaptoethanol ( $\beta$-ME) and separated on a 10\% SDS gel. Western blot was carried out using the anti-EmIR2 antiserum. D) Immunodetection of EmIR1 and EmIR2 in different larval stages using immune sera. Parasite larvae were lysed, protein preparations were then separated by SDS-PAGE, blotted onto a membrane and detected by the antisera. The purified anti-EmIR2 immune serum recognized the EmIR2 $\beta$-subunit at $87 \mathrm{kDa}$ and a second band at $60 \mathrm{kDa}$. The EmIR1 $\beta$-subunit was detected at $150 \mathrm{kDa}$ using the anti-EmIR1 immune serum. Actin was used as a loading control. Mc, metacestode vesicles; Pc, primary cells; Ps-, dormant protoscoleces; Ps+, activated protoscoleces.

these results were unexpected and indicated that the expression of EmIR1 and EmIR2 in primary cell cultures and metacestode vesicles, respectively, might be subject to translational repression.

Using the anti-EmIR1 antiserum, we next investigated the localization of EmIR1 in Echinococcus larval stages by immunohistochemistry, immunofluorescence and electron microscopy. As expected from the Western blot experiments mentioned above, no EmIR1 staining was obtained for primary cell cultures (data not shown). Most strikingly, however, we observed particularly strong staining for a population of large, round cells present at the proximal layer of the metacestode (Figure 4). These cells clearly represented the parasite's glycogen storing cells (GSC), in which glycogen is not preserved when fixed without tannic acid. These results could be verified by transmission electron microscopy using immune-gold labelled antiEmIR1 antiserum. Again, strong signals were obtained for GSC (Figure 5), but weaker signals associated with other cell types, such as undifferentiated parasite stem cells, were also observed (data not shown). For EmIR2, staining of the parenchyma close to the surface of the protoscolex was obtained as well as a diffuse staining pattern throughout primary cell aggregates (Figure 6). For metacestode vesicles, on the other hand, no EmIR2 signal was obtained (data not shown).

Using an established protocol applicable to metacestode vesicles, we also investigated emir2 expression by in situ hybridisation. In these experiments, no signal was obtained for the germinal layer of vesicles that had not yet started to develop protoscoleces (data not shown). However, in fertile vesicles an intense emir 2 signal was 


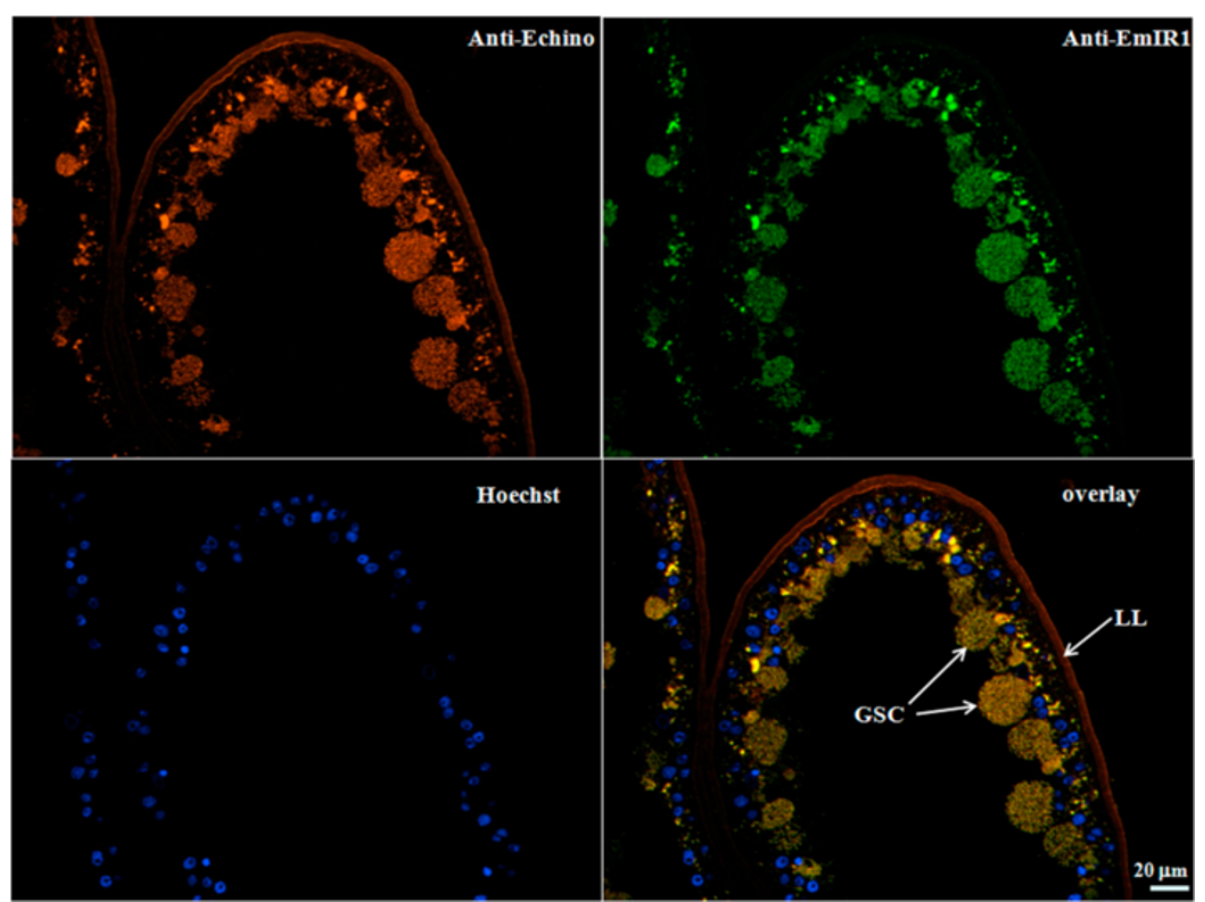

Figure 4 EmIR1 immunohistochemistry on metacestode vesicles. Cryosections of in vitro cultivated metacestode vesicles were probed with the anti-EmIR1 antiserum (anti-EmIR1) and detected with a FITC-coupled anti-rabbit-antibody. Nuclei were visualized by Hoechst-staining (Hoechst). Parasite surface structures were visualized using a general anti-Echinococcus metacestode antibody (Anti-Echi; Ingold et al., 2001 [50]). $\mathrm{LL}$, laminated layer; GSC, glycogen storing cells. FITC, fluorescein isothiocyanate.

associated with the proliferation zone of developing protoscoleces, in which parasite stem cells undergo cell division, as indicated by the incorporation of the thymidine analogue 5-ethylnyl-2'-deoxyuridine (EdU) (Figure 7). These data indicated that emir2 might be specifically expressed in parasite stem cells or, at least, in parasite tissues that are actively proliferating.

Taken together these results demonstrated that EmIR1 is present in metacestode vesicles where it is primarily associated with GSC. Since host insulin is present not only outside of metacestode vesicles but highly likely also within hydatid fluid, which contains a large number of host serum proteins [24], the localisation of EmIR1 also suggests that it has direct contact with host insulin. EmIR2, on the other hand, was not present in metacestode vesicles (or at concentrations below the detection limit of the staining method), but dispersed throughout primary cell aggregates. Furthermore, emir2 expression was prominent in developing protoscoleces which suggests an association with parasite stem cells.

\section{Host insulin stimulates glucose uptake by metacestode vesicles}

The prominent localisation of EmIR1 in GSC indicated that this receptor could be involved in Echinococcus glucose uptake/storage mechanisms. To investigate this aspect, metacestode vesicles were cultivated in the presence of radioactively labelled glucose and were either stimulated with host insulin or not. As shown in Figure 8, the addition of $10 \mathrm{nM}$ insulin to metacestode vesicles significantly stimulated glucose uptake after one hour of incubation, which was even more pronounced after addition of the phosphatase inhibitor $\mathrm{Na}_{3} \mathrm{VO}_{4}$, indicating that phosphorylation events are involved in regulating Echinococcus glucose uptake or transport. Hence, similar to the situation in intermediate host hepatocytes, insulin also regulates glucose uptake by parasite cells.

\section{Host insulin affects parasite signalling pathways}

Next, we investigated parasite signalling pathways that could be involved in insulin sensing and signalling. First, we concentrated on EmIR1, which showed prominent expression in GSC of metacestode vesicles. The membrane fraction of metacestode vesicles was isolated and the presence of EmIR1 in this fraction was verified by Western blotting (Figure 9A). The proteins in the membrane fraction were then stimulated with human insulin for 30 minutes in the presence of $\left[{ }^{32} \mathrm{P}\right]-\gamma \mathrm{ATP}$. As a control, human IGF was tested which, unlike insulin, has previously been shown not to interact with the EmIR1 LBD in yeast two-hybrid experiments [11]. After stimulation, EmIR1 was immunoprecipitated from the membrane fraction and phosphorylation was analysed by gel 

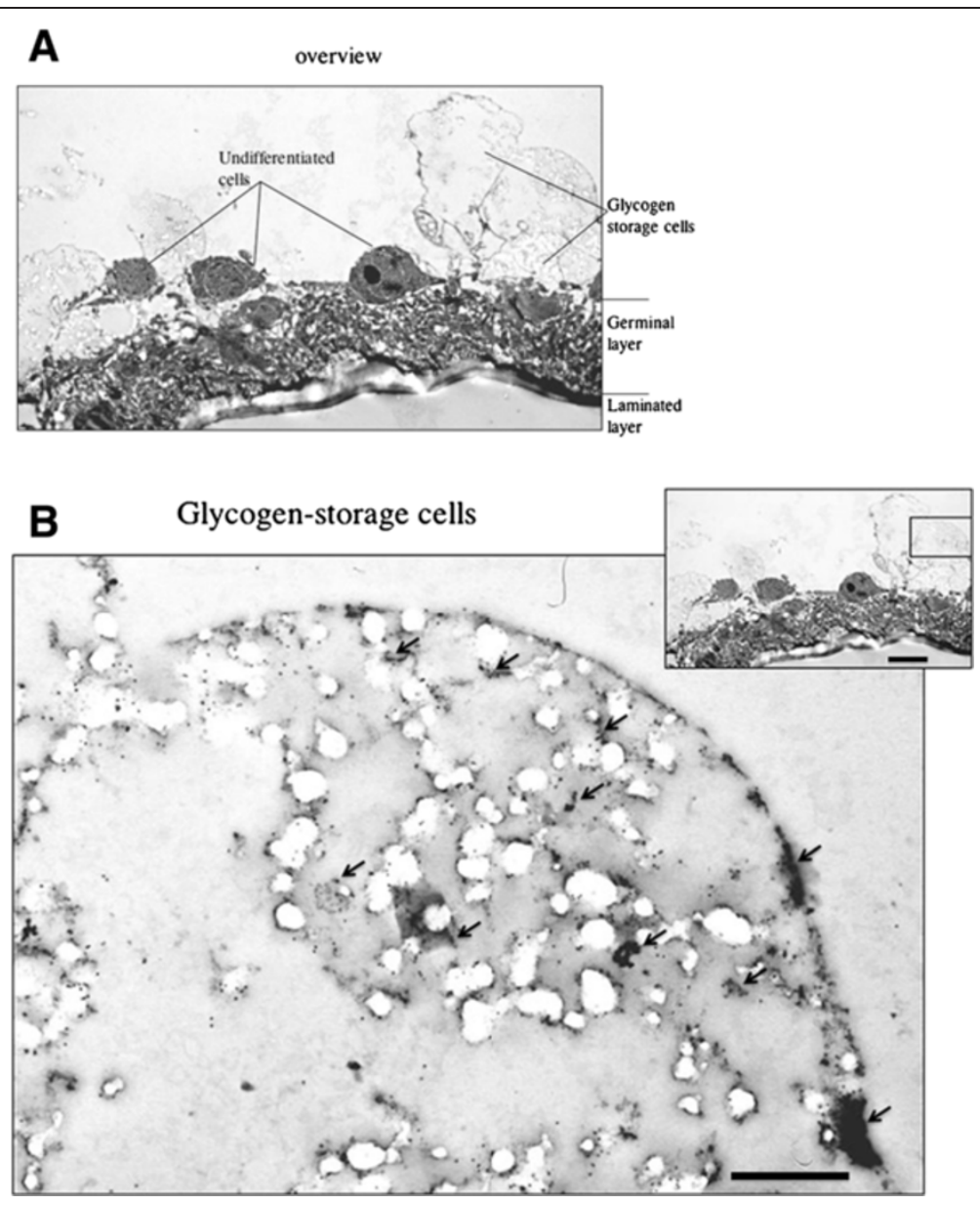

Figure 5 EmIR1 electron microscopic analyses. The anti-EmIR1 antiserum and gold-coupled anti-rabbit antibodies were used to detect EmIR1 in the metacestode germinal layer. A) Overview showing the location of the laminated layer, the germinal layer, undifferentiated (stem) cells and glycogen storage cells. B) Glycogen storage cell showing massive anti-EmIR1 staining (arrows). Scale bar in larger image represents $0.6 \mu \mathrm{m}$, scale bar in insert represents $3.6 \mu \mathrm{m}$.

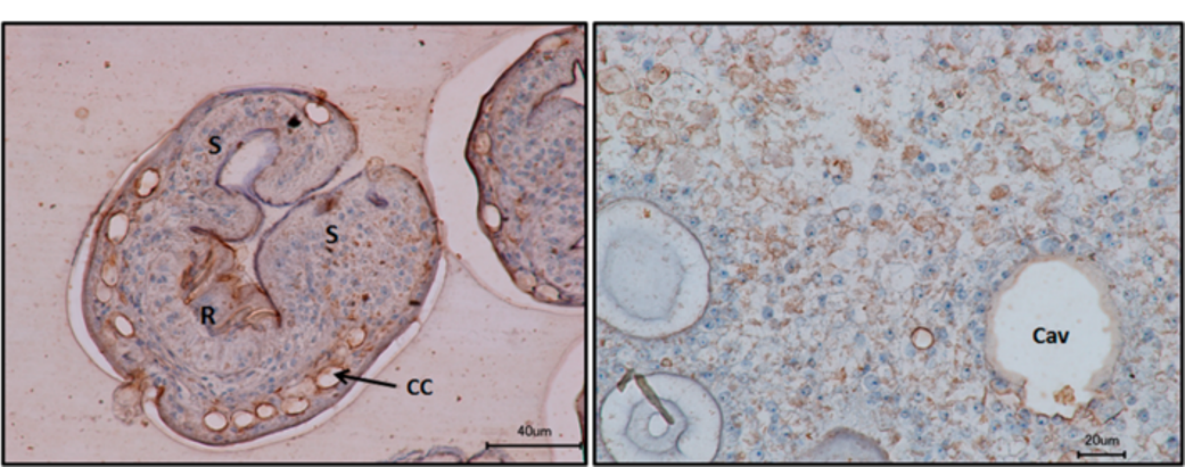

Figure 6 Anti-EmIR2 immunohistochemistry. Sections of E. multilocularis protoscolex preparations (left panel) and primary cell culture aggregates (right panel) have been probed with the anti-EmIR2 antiserum. Brown color indicates positive signals. Cav, central cavity; S, suckers; R, rostellum; CC, calcareous corpuscles. 


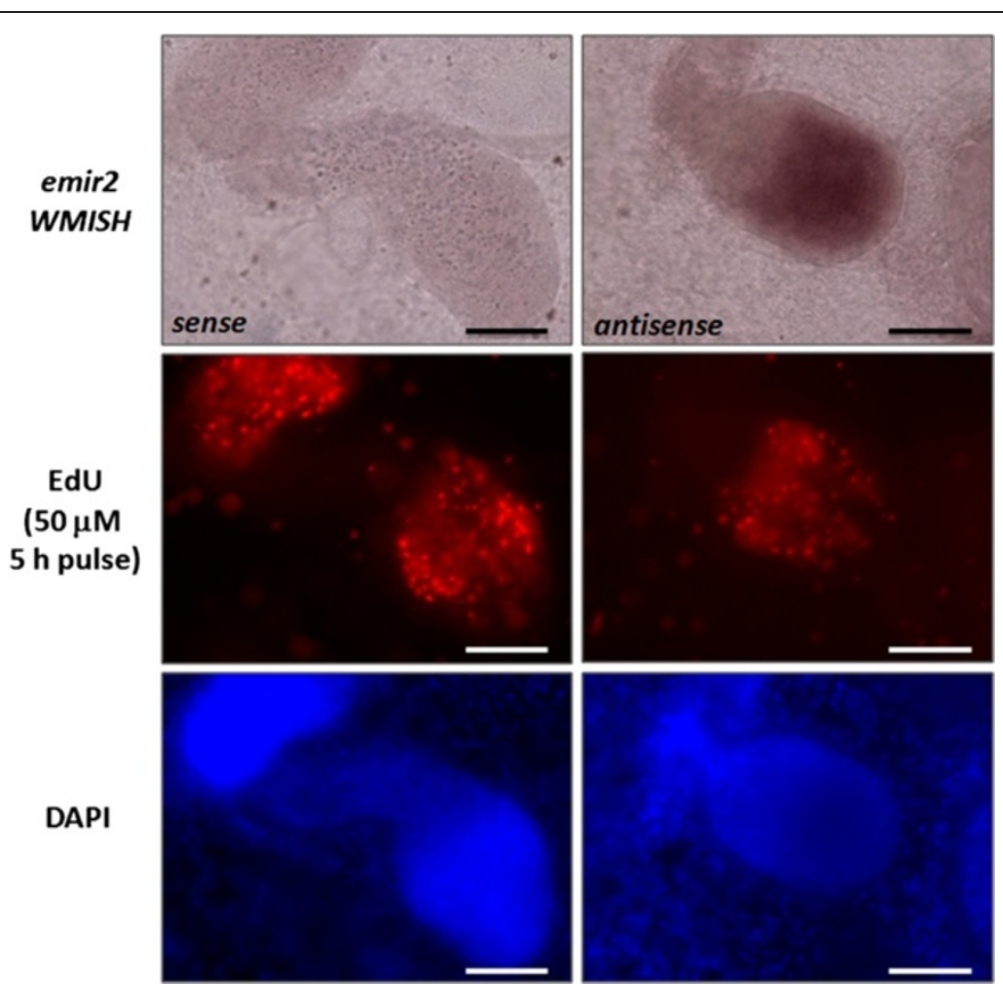

Figure 7 Whole mount in situ hybridisation (WMISH) detection of emir2. Germinal layer with developing protoscoleces stained for emir2 WMISH (upper panel), EdU incorporation (mid panel) and DAPI (lower panel). Sense (left) and antisense (right) probes have been used as indicated. Bar represents 50 m. DAPI, 4',6-diamidino-2-phenylindole; EdU, 5-ethylnyl-2'-deoxyuridine.



electrophoresis and autoradiography (Figure 9B). In order to ensure maximal activation of the receptor in this complex immunoprecipitation experiment, saturating hormone concentrations of $100 \mathrm{nM}$ were used, as usual for comparable experiments on insulin receptors [25-30]. As depicted in Figure 9B, EmIR1 protein phosphorylation was detected after stimulation with insulin, but not with IGF. Protein bands smaller than the expected size of the EmIR1 $\beta$-subunit (Figure 9B) were most probably due to degradation of membrane proteins in this experimental setting.

We also employed a specific compound, HNMPA $(\mathrm{AM})_{3}$, that was originally designed to inhibit the human insulin receptor [13] and was subsequently found to also inhibit schistosome insulin receptors [13,31]. To confirm that $\operatorname{HNMPA}(\mathrm{AM})_{3}$ is principally also able to inhibit EmIR1, in silico modelling of the EmIR1 TKD was carried out and revealed that $\operatorname{HNMPA}(\mathrm{AM})_{3}$ has comparable affinities for the EmIR1 TKD and the HIR TKD [see Additional file 5]. Interestingly, when stimulated by insulin in the presence of $100 \mu \mathrm{M} \mathrm{HNMPA}(\mathrm{AM})_{3}$, no phosphorylation of EmIR1 immunoprecipitates was observed (Figure 9B), indicating that this compound prevents EmIR1 activation.

We also investigated specific tyrosine phosphorylation of EmIR1 after insulin treatment of metacestode vesicles. 


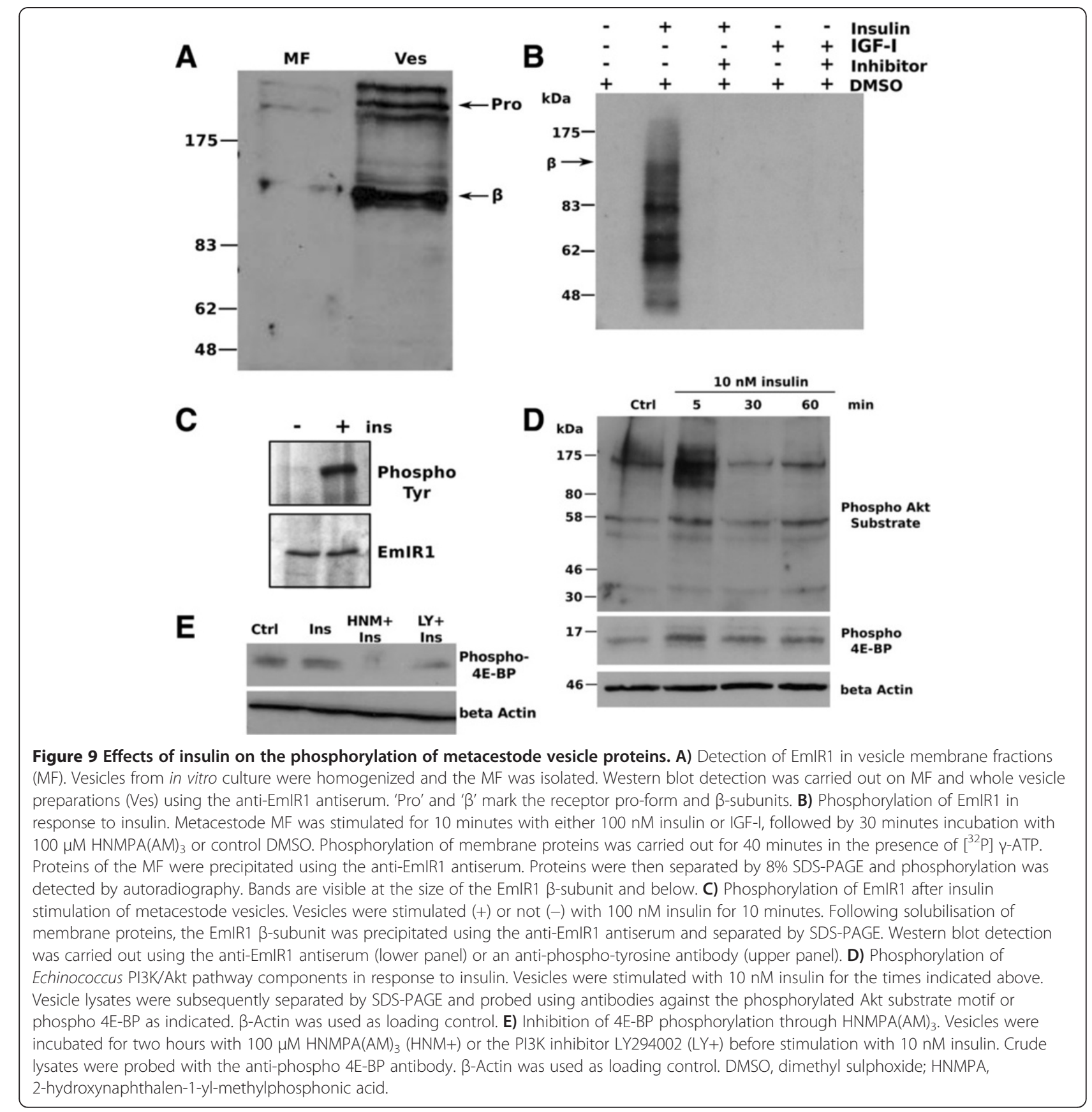

To this end, intact in vitro cultivated metacestode vesicles were stimulated with $100 \mathrm{nM}$ insulin (to ensure maximum activation) for 10 minutes, followed by immunoprecipitation of EmIR1, using the anti-EmIR1 antiserum. Subsequently, detection of phosphorylated tyrosine using an anti-phospho-tyrosine antibody was carried out. As shown in Figure 9C, insulin treatment indeed induced tyrosine phosphorylation of the EmIR1 $\beta$-subunit in these vesicles.

In other organisms, signalling pathways that act downstream of insulin receptors usually involve phosphorylation of several intracellular signalling factors. Among the signalling pathways that are stimulated by insulin in many organisms is the ERK-like MAPK cascade [7-9], a complete module of which we had previously characterized in $E$. multilocularis [32,33]. When we analysed the activation of the Echinococcus MAPK cascade in response to exogenously added insulin by measuring phosphorylation of the ERK-like MAPK EmMPK1 [32], however, only a very weak induction was observed (data not shown). We, therefore, concentrated in additional experiments on the PI3K/Aktpathway, another major downstream target of insulin 
signalling in vertebrates and invertebrates [7-9]. So far, this pathway had not been addressed in Echinococcus or other parasitic helminths. We, therefore, first screened the available E. multilocularis genome sequence [22] and could indeed identify genes encoding several key components of this pathway, such as a catalytic subunit of PI3K, an ortho$\log$ to mTOR (mammalian target of rapamycin), a glycogen synthase kinase-ortholog, and orthologs to protein kinase B (also called Akt kinase) or the eukaryotic translation initiation factor 4E-binding protein (4E-BP) [see Additional file 6]. We were particularly interested in the genes encoding the E. multilocularis orthologs of Akt [see Additional file 7] and 4E-BP [see Additional file 8] and fully cloned and sequenced the respective cDNAs. Next, we used antibodies that either detect the phosphorylated form of the evolutionarily conserved Akt kinase target motif RxRxxS/T or the phosphorylated form of $4 \mathrm{E}-\mathrm{BP}$ in a region that is highly conserved among orthologs of different species [see Additional file 8] to study the effects of insulin on the PI3K/Akt pathway. As depicted in Figure 9D, some basic level of phosphorylation was detected both for Akt substrates and 4E-BP, which is most probably due to the fact that serum-containing media inevitably contain residual concentrations of insulin, which cannot be completely removed. However, particularly after a five minute treatment of metacestode vesicles with $10 \mathrm{nM}$ exogenous insulin, a marked phosphorylation of several additional proteins could be observed using the anti-phospho-Aktsubstrate antibody. Furthermore, using the anti-phospho4E-BP antibody, a clearly enhanced phosphorylation of a single protein with a molecular mass within the range of 4E-BPs was detected. We then also investigated whether 4E-BP phosphorylation in response to insulin can be inhibited by HNMPA(AM)3 (pre-incubation with $100 \mu \mathrm{M}$ inhibitor) and found that this was indeed the case (Figure 9E).

Taken together, these results indicated that exogenously added insulin directly stimulated EmIR1 in intact metacestode vesicles and that insulin treatment also led to an activation of the PI3K/Akt-pathway in Echinococcus.

\section{An insulin receptor inhibitor blocks parasite development in vitro.}

Since the insulin receptor inhibitor $\operatorname{HNMPA}(\mathrm{AM})_{3}$ prevented the phosphorylation of EmIR1 in metacestode membrane fractions (see above), we further investigated the effects of this small molecule compound on parasite development. First, we investigated larval development from stem cell cultures to metacestode vesicles and observed that vesicle formation was almost completely abolished at concentrations of 25 and $50 \mu \mathrm{M}$ of HNMPA(AM) $)_{3}$ (Figure 10A,B). These concentrations also significantly decreased protoscolex viability (Figure 10C), but were ineffective in killing metacestode vesicles, at least after seven days of incubation (data not shown). In the presence of $100 \mu \mathrm{M} \mathrm{HNMPA}(\mathrm{AM})_{3}$, on the other hand, only $20 \%$ of metacestode vesicles survived after seven days (Figure 10D). Taken together, these data indicated that intact insulin receptor signalling is important for parasite survival and development.

\section{Characterization of insulin-like peptides in E. multilocularis}

As yet, the presence of genes that encode insulin-like peptides has been described for the free-living flatworm $S$. mediterranea [16] but not in any parasitic flatworm. We, therefore, screened the E. multilocularis genome [22] by BLAST analyses for the presence of such genes. Indeed, we found two genes located immediately adjacent to each other (separated by $17 \mathrm{~kb}$ ) on contig 60709 of the current assembly, which code for peptides with moderate overall homology to human insulin, but which display classical signatures of insulin-like peptides (ILPs) (Figure 11A). Both genes, named emilp1 (EmuJ 000045300) and emilp2 (EmuJ_000045400), code for peptides that, according to SMART analyses, contain an IIGF domain (insulin/insulin-like growth factor/relaxin) and an export-directing signal peptide (Figure 11A), indicating that they are secreted. By RT-PCR analyses it was very difficult to amplify emilp1 and emilp2 transcripts from RNA preparations of primary cells, metacestode vesicles and protoscoleces (data not shown), indicating that both genes are very slightly expressed in parasite larval stages. Accordingly, in available transcriptome data sets for E. multilocularis [22], emilp1 and emilp2 show highest expression levels in the adult stage [see Additional file 3], whereas only moderate expression was found for emilp2 in parasite larvae and no expression of emilp1 in primary cells and metacestode vesicles [see Additional file 3].

The interaction between ILPs and cognate receptors has previously been investigated using the yeast twohybrid system $[10,11,13]$ and we employed this approach to also study interactions between human insulin, the parasite ILPs and possible cognate receptors. As shown in Figure 11B, human pro-insulin interacted strongly with the LBD of HIR and both parasite insulin receptors. EmILP1 and EmILP2, on the other hand, only showed detectable interaction with EmIR2, whereas none of the parasite ILPs interacted with EmIR1 or HIR.

Taken together, these analyses demonstrate that the $E$. multilocularis genome encodes ILPs, but the respective genes appear to be mainly involved in developmental processes of the adult stage which resides in the definitive host's gut and, thus, has no access to host-derived insulin. As previously shown [10], human insulin could interact with EmIR1 and we now demonstrated that it also interacts with the LBD of EmIR2. Finally, of all ILPs tested, only human insulin appeared capable of acting as a ligand for EmIR1. 


\section{Discussion}

Since the initial characterization of a member of the insulin receptor family in E. multilocularis, EmIR1 [10], few studies have been conducted to investigate the effects of mammalian insulin on flatworm parasite insulin signalling pathways and development. In each of the related parasites Schistosoma mansoni and S. japonicum, two EmIR1-like tyrosine kinases of the insulin receptor family were identified and, as originally shown for EmIR1, the possibility of an interaction of these receptors with host insulin was verified using the yeast twohybrid system $[11,13]$. These studies did, however, not address whether host-derived insulin would stimulate (or generally influence) parasite development and/or establishment within the host. Although Ahier et al. [12] later investigated effects of host insulin on glucose uptake of S. mansoni in vitro, significant stimulation was only achieved using hormone concentrations of $1 \mu \mathrm{M}$, which can be considered non-physiologically high since plasma levels of insulin in humans and animals usually range between 1 to $2 \mathrm{nM}[34,35]$. Likewise, in studies on cestode systems conducted by Canclini and Esteves [15] (Mesocestoides corti) and Escobedo et al. [14] (Taenia crassiceps), effects on glucose metabolism or parasite development ( $T$. crassiceps budding) were only observed at insulin concentrations several magnitudes higher than physiological concentrations. Hence, although several investigations had already addressed the possibility of insulin-based hormonal cross communication between flatworm parasites and mammalian hosts, it is still unclear to date whether host insulin at physiological concentrations indeed influences parasite development and
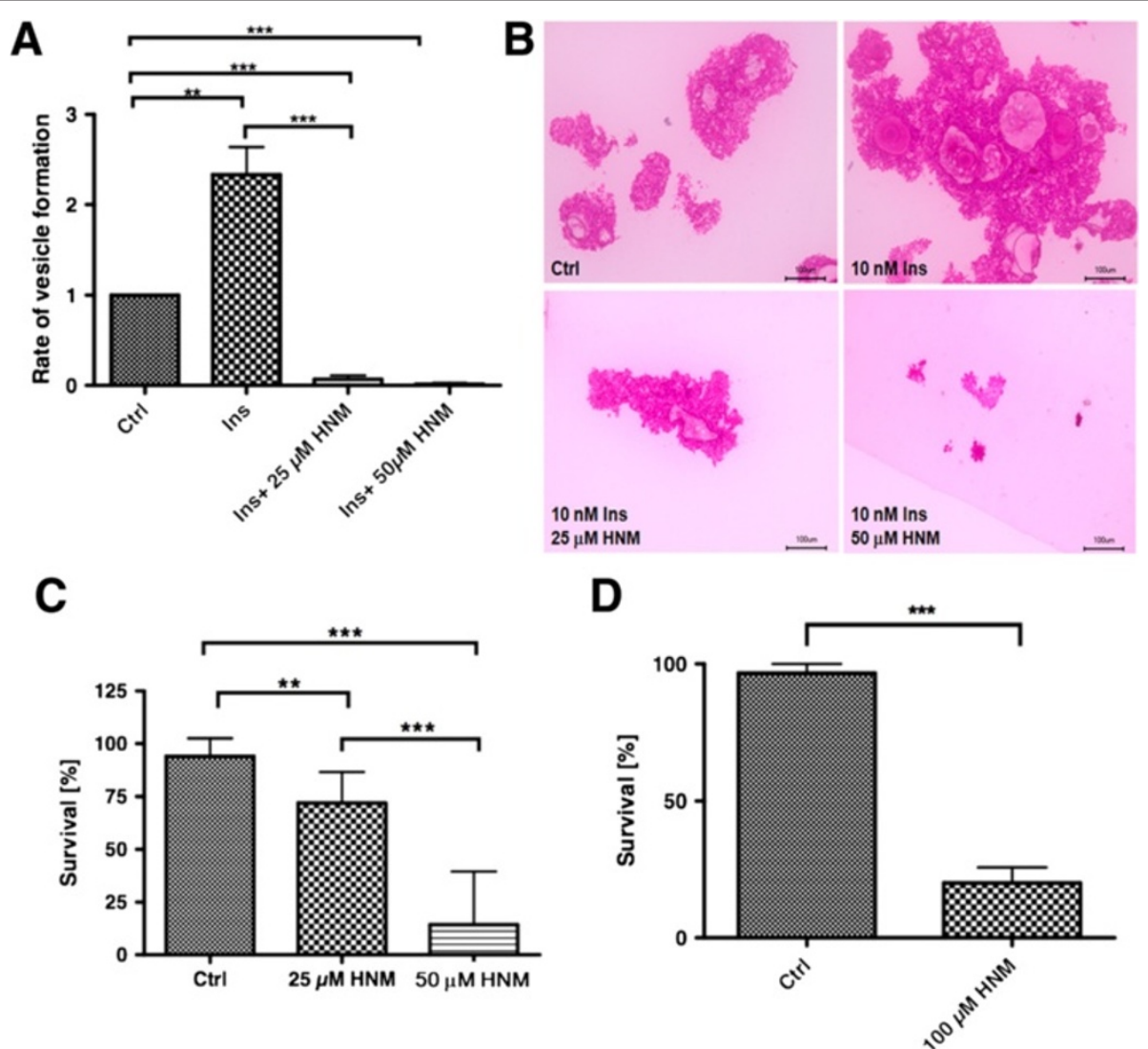

Figure 10 Effects of $\mathrm{HNMPA}(\mathrm{AM})_{3}$ on parasite larvae. A) Primary cells were isolated from axenic metacestode vesicles and cultivated in $2 \%$ FCS/(D)MEM supplemented with $10 \mathrm{nM}$ human insulin, with or without HNMPA(AM) 3 . After three weeks of incubation, mature vesicles were counted. Insulin was added to the cultures in order to obtain vesicle formation within three weeks. B) Formation of primary cell aggregates in the presence of HNMPA(AM) 3 . Primary cells were incubated as in (A) for seven days before aggregates were fixed, embedded in Technovit 8100 and $4 \mu \mathrm{m}$ sections stained with haematoxylin/eosin. Note the profound effect of HNMPA(AM) 3 on parasite aggregates already after seven days. Ctrl, DMSO control. C) Protoscoleces were treated with $\mathrm{HNMPA}(\mathrm{AM})_{3}$ for two weeks under axenic conditions. Protoscolex viability was analysed by counter-staining with methylene blue. D) Metacestode vesicles were treated for one week with $100 \mu \mathrm{M} \mathrm{HNMPA(AM)})_{3}$ under axenic conditions. Survival was assessed by counting physically damaged vesicles. Vesicles were incubated in the presence of conditioned medium for optimal maintenance and survival conditions. $\left(^{*}\right) P$ values below $0.05,\left({ }^{* *}\right)$ very significant for $P$ between 0.001 and 0.01 , $\left(^{* * *}\right)$ extremely significant for $P<0.001$. DMSO, dimethyl sulphoxide; HNMPA, 2-hydroxynaphthalen-1-yl-methylphosphonic acid. 
metabolism or whether such effects are mediated by evolutionarily conserved insulin signalling systems of these parasites.

In the present study, we concentrated on a cestode, $E$. multilocularis, the larval stage of which displays a strong organ-tropism towards the liver where the highest insulin concentrations (up to $15 \mathrm{nM}$ ) within mammals can be measured [4-6]. Several independent lines of evidence clearly indicate that $E$. multilocularis larvae are responsive to exogenously added host-insulin at physiological concentrations. First, $10 \mathrm{nM}$ insulin significantly increased the production of metacestode vesicles from parasite stem cells as well as the re-differentiation of protoscoleces towards metacestode vesicles, and also significantly stimulated parasite stem cell proliferation in primary cell cultures and metacestode vesicles, as measured by the incorporation of BrdU. Second, the uptake of radioactively labelled glucose by metacestode vesicles was significantly stimulated in the presence of $10 \mathrm{nM}$ host insulin. Third, exogenously added host insulin clearly affected the phosphorylation profiles of components of the PI3K/Akt signalling pathway in the metacestode. On the basis of these data, we propose that insulin constitutes an important host factor that influences the development and physiology of E. multilocularis larvae within the liver. The observed effects were most striking for initial metacestode development from stem cells, which could aid the parasite in establishing itself early during an infection, when it is most vulnerable to attacks by the host immune system [36]. Compared to primary cells, somewhat lower effects were observed on the proliferation of mature metacestode vesicles, which could be due to the fact that this stage contains significantly lower proportions of stem cells that are capable of proliferation than the primary culture system (Koziol et al., submitted for publication). On the other hand, given the important role of glycogen as the main energy source for larval cestode metabolism, the observed effects of host insulin on glucose uptake by $E$. multilocularis could be important for long-term persistence of the parasite within the host. Whether the insulin-stimulated redifferentiation of protoscoleces towards the metacestode is important in vivo still remains to be determined. Protoscolex re-differentiation in experimental secondary echinococcosis or following accidental or surgery-induced rupture of parasite cysts is a well described phenomenon [2,3] and at least for E. granulosus it is thought that parasite persistence within the host is aided by re-differentiation of existing protoscoleces once the mother hydatid cyst experienced
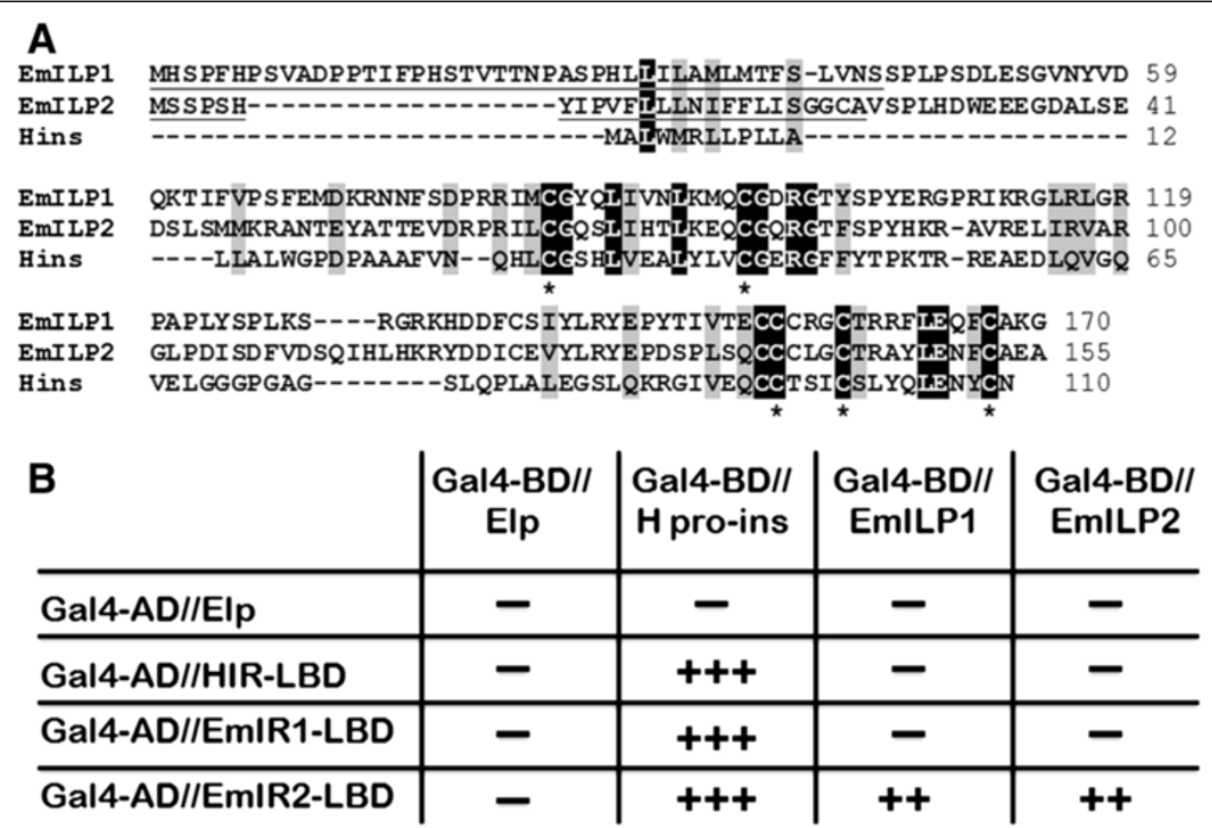

Figure 11 E. multilocularis insulin-like peptides and yeast two-hybrid experiments. A) Amino acid sequence comparison between the $E$. multilocularis insulin-like peptides EmILP1 and EmILP2 and human insulin (Hins). Highly conserved residues are printed in white on black background, residues with similar biochemical features are printed in black on grey background. Underlined sequences indicate predicted signal peptides. Asterisks indicate cysteine residues important for disulphide-bridge formation. B) Yeast two-hybrid experiments. Translational fusions were generated for the Gal4 activation domain (Gal4-AD) and the LBDs of the human insulin receptor (HIR-LBD) as well as the E. multilocularis receptors EmIR1 (EmIR1-LBD) and EmIR2 (EmIR2-LBD). The Gal4 DNA binding domain (Gal4-BD) was fused to human pro-insulin (H pro-ins) as well as to EmILP1 and EmILP2. Yeast strains were double transformed with the plasmid constructs as indicated and growth under different stringency conditions [10] was assessed. '-' indicates no growth, '++' growth under medium stringency conditions, ' +++ ' growth under high stringency conditions. LBDs, ligand binding domains. 
physical damage [3]. In this regard, the influx of elevated concentrations of host insulin into ruptured parasite cysts, followed by increased re-differentiation of protoscoleces, may well contribute to prolonged parasite survival. However, whether these mechanisms are also relevant to $E$. multiocularis infections is still not clear. In any case, the observed effects of $1 \mathrm{nM}$ and $10 \mathrm{nM}$ insulin on protoscolex re-differentiation again demonstrate that $E$. multilocularis larvae are well responsive to physiological concentrations of insulin.

Since our data revealed that insulin significantly stimulates metacestode vesicle formation from primary cell cultures in a system that mimics the natural oncospheremetacestode-transition, it is, of course, tempting to speculate that the relatively strict organ-tropism of $E$. multilocularis towards the host liver $[1,2]$ may, at least in part, depend on the high insulin concentrations usually present in this organ. Although this is supported by our data showing that host insulin stimulates proliferation of $E$. multilocularis stem cells, which is in line with the role of insulin signalling in proliferation control of neoblasts in free-living flatworms [16], further experiments addressing insulin effects on naturally isolated oncospheres are necessary to obtain a conclusive picture. This would also require comparative analyses on oncospheres from E. granulosus, which display a relaxed liver organ tropism, and those of Taenia solium (or Taenia saginata), which usually don't develop in the host liver, despite an entry route into the host comparable to that of E. multilocularis [2]. It is interesting to note in this context that Escobedo et al. [14] did not observe effects on T. solium cysticerci under high insulin treatment conditions that stimulated larval budding in $T$. crassiceps. However, care has to be taken in the interpretation of their results, since for $T$. solium the authors measured scolex evagination which is not, per se, a developmental process.

According to the theory of hormonal host-helminth cross-communication, endo- and paracrine hormonal systems of mammals (or even invertebrates) could influence the physiology and development of metazoan parasites through stimulation of evolutionarily conserved signalling systems [2,37-39]. This theory has thus far been supported by several in vitro studies showing that parasite surface receptor kinases of the insulin-, the EGF- and the TGF- $\beta$-families can principally bind respective host-derived hormones [10,11,13,37-41]. One of the most convincing examples supporting this theory has been brought up by Vicogne et al. [41] who demonstrated that human EGF can activate an EGF-receptor, such as tyrosine kinase of S. mansoni in vitro and at the surface of schistosomes, and that exogenously added EGF also influences protein and DNA synthesis in the parasite. We now propose the host-insulin-E. multilocularis-EmIR1 system as another example that supports this theory. Again, several lines of evidence clearly indicate that at least some of the effects of host insulin on E. multilocularis development and physiology involve binding of the host hormone to the insulin-receptor-like tyrosine kinase EmIR1. First, exogenously added host insulin influences EmIR1 phosphorylation patterns in the metacestode which is prevented in the presence of an anti-insulin-receptor inhibitor. Second, host insulin particularly influenced the phosphorylation of components of the PI3K/Akt pathway, which is known to act downstream of insulin-receptor tyrosine kinases in many organisms [7-9], and this was prevented in the presence of an insulin receptor inhibitor. Since the stimulation of the PI3K/Akt pathway through insulin receptors requires IRSs as intermediate signalling molecules [42], a binding site for which is present in EmIR1 (but not in EmIR2), the activation of this pathway in E. multilocularis most likely involves EmIR1. Third, although E. multilocularis encodes ILPs, the expression levels of the respective genes in the metacestode are very low and none of the parasite ILPs interacted with EmIR1 in yeast two-hybrid assays, indicating that host insulin is the only EmIR1 activating hormone present in significant concentrations around the growing metacestode. In this respect, it is even tempting to speculate that EmIR1 entirely lost the capacity to be stimulated by parasite-encoded ILPs since it is most active in parasite stages that have contact with elevated concentrations of host insulin. We, thus, propose that several of the actions of insulin on the $E$. multilocularis metacestode, particularly the stimulation of glucose uptake and the stimulation of metacestode proliferation, are mediated by direct binding of the host hormone to EmIR1, followed by subsequent activation of insulin-dependent parasite signalling pathways. This should be particularly relevant in the Echinococcus GSCs, which display the highest expression levels of EmIR1 and are the cell type responsible for carbohydrate storage.

Although EmIR1 at the protein level was not detected in the E. multilocularis primary cell cultivation system, we could observe clear effects of host insulin on the formation of metacestode vesicles from parasite stem cells. These effects are, thus, most probably mediated independently of EmIR1 and in the present study we identified a second E. multilocularis insulin receptor molecule, EmIR2, which could be involved in the effects on parasite stem cells. On the one hand, our histochemical analyses showed that EmIR2 expression is dispersed through primary cell aggregates, which contain a large number of parasite stem cells [19]. Furthermore, the in situ hybridization experiments presented in this work clearly indicate that at least in developing protoscoleces, emir2 transcripts are closely associated with the proliferation zone where parasite stem cells are most active (Koziol et al., submitted for publication), indicating a link between EmIR2 and stem cell 
proliferation or differentiation. The presence of two insulin receptor encoding genes in E. multilocularis closely resembles the situation in the related schistosomes, which also express two molecules of this class [11-13]. As with the schistosome receptor LBDs, which interacted with human insulin in the yeast two-hybrid system $[11,13]$, we herein demonstrated that in addition to EmIR1, EmIR2 can also interact with the host hormone. Since the Echinococcus emilp2 gene was expressed at low, but detectable, levels in primary cells and since the encoded peptide, EmILP2, interacted with EmIR2 in the yeast twohybrid system, we cannot exclude that a certain level of stimulation of EmIR2 by EmILP2 in primary cells could contribute to initial parasite development within the liver. However, our experiments clearly indicate that physiological levels of human insulin, that should be present at the site of initial parasite development from the oncosphere, can significantly add to these effects. Hence, it is conceivable that during the oncosphere-metacestode transition both EmILP2 and human insulin bind to EmIR2, which could lead to higher activation of the parasite receptor than through EmILP2 alone, and which could thus promote rapid parasite establishment. Whether this indeed occurs in vivo and which parasite signalling pathways act downstream of EmIR2, given that it lacks the conserved NPXY motif, still remains to be established. Unfortunately, and in contrast to the metacestode vesicle culture system, membrane fractionation and insulin stimulation studies are very difficult to carry out on the stem cell cultivation system due to the fragility of stem cell aggregates and their high sensitivity to serum-free cultivation conditions. Nevertheless, given that EmIR2 is capable of interacting with human insulin in the yeast two hybrid system and that it is expressed as the only parasite insulin receptor in the primary cell system, hormonal host-parasite crosscommunication through insulin-binding to EmIR2 could indeed play a significant role in parasite establishment within the liver.

Ahier et al. [11] and You et al. [13] previously used inhibitors specifically designed to bind to insulin receptorlike kinases and observed deleterious effects on the uptake and consumption of glucose by schistosomes, indicating that at least the mechanisms of glucose uptake, similar to Echinococcus as shown in this study, are under the control of insulin signalling in these parasites. In the present study, we employed $\operatorname{HNMPA}(\mathrm{AM})_{3}$, the same inhibitor used by You et al. [13], and observed various effects on the development of metacestode vesicles from primary cells, on the survival of mature metacestode vesicles and on the re-differentiation process from protoscoleces towards the metacestode. In mature metacestode vesicles, only relatively high concentrations $(100 \mu \mathrm{M})$ of $\mathrm{HNMPA}(\mathrm{AM})_{3}$ led to killing and we suggest that this mostly involved binding of the drug to EmIR1, accompanied by defects in glucose uptake and consumption. That the drug can principally bind to EmIR1 is supported by our in silico analyses showing that the parasite receptor's ATP-binding pocket is capable of harbouring $\mathrm{HNMPA}(\mathrm{AM})_{3}$ with considerable affinity. Compared to mature metacestode vesicles, the effects of $\mathrm{HNMPA}(\mathrm{AM})_{3}$ on primary cells were much more dramatic. Already at a concentration of $25 \mu \mathrm{M}$, the insulin receptor inhibitor completely prevented the formation of metacestode vesicles from parasite stem cells. Since EmIR1 is not expressed in this parasite stage, we suggest that EmIR2 is also capable of binding $\operatorname{HNMPA}(\mathrm{AM})_{3}$, maybe even with higher affinity than EmIR1. Indeed, in a recent report Vanderstraete et al. [31] demonstrated that HNMPA(AM)3 inhibits the schistosome receptor SmIR1 (which is the ortholog to EmIR2) with much higher efficacy (10 to 100 fold more) than SmIR2 (ortho$\log$ to EmIR1). When applied to the Echinococcus system, this could explain the relative resistance of the (EmIR1 expressing) metacestode to the drug when compared to the (EmIR2 expressing) primary cell system. However, care has to be taken in the interpretation of data on insulin inhibitor effects on flatworms since Vanderstraete et al. [31] also showed that these can affect a structurally diverse family of receptor kinases that are composed of an extracellular Venus FlyTrap (VFT) motif and an intracellular, insulin receptor-like TKD. In S. mansoni, two of these kinases, named SmVKR1 and SmVKR2, are expressed and a panel of available insulin receptor inhibitors that showed effects on SmIR1 and SmIR2 also affected SmVKR1 and SmVKR2 in a similar manner [31]. In the E. multilocularis genome, only one gene encoding such a tyrosine kinase, EmVKR, is present and transcriptome data indicate that it is expressed in a similar manner as emir2 (data not shown). For the inhibitor data concerning EmIR1 phosphorylation upon addition of insulin, we do not see interpretation problems since this was carried out specifically for EmIR1, immunoprecipitated from membrane fractions. However, at least some of the effects we observed on entire Echinococcus larvae after application of $\operatorname{HNMPA}(\mathrm{AM})_{3}$ could indeed be due to inhibition of EmVKR rather than EmIR1 and EmIR2. Unfortunately, it is presently not possible to clearly distinguish between these possibilities since highly selective inhibitors for the parasite insulin receptors versus the VKR receptors are not available [31] and since RNAi methodology for E. multilocularis is still in its infancy. Nevertheless, our data indicate that the insulin signalling system of E. multilocularis, including insulin receptor kinases, EmVKR, and downstream signalling components, might be a fruitful target for the development of novel chemotherapeutics, as has previously been argued in the case of schistosomes [11-13,31]. 
In summary, our data indicate an important role of host insulin on the development of E. multilocularis larvae within the host's liver. We also showed that this involves hormonal host-parasite cross-communication via evolutionarily conserved signalling systems, which is particularly striking for EmIR1 concerning glucose uptake in GSCs of the metacestode and, most likely, also applies to EmIR2 in the primary cell system. Using a well-known inhibitor of insulin receptor signalling, we also demonstrated clear effects on parasite survival and, particularly, development. Although $\operatorname{HNMPA}(\mathrm{AM})_{3}$ might not be as efficient as other kinase inhibitors, such as pyridinyl imidazoles [43] or imatinib [44], in inducing killing of the metacestode, which is the main target of chemotherapy against alveolar echinococcosis, our study now opens the way for the development of more specific inhibitors that could be used to affect glucose uptake by the parasite during development. Furthermore, due to their obvious effects on parasite stem cell proliferation, insulin receptor inhibitors might be used to inhibit asexual multiplication of an already established parasite mass or to prevent metastasis formation from stem cells in advanced cases of the disease [2]. Since the somewhat lower efficacy of $\operatorname{HNMPA}(\mathrm{AM})_{3}$ to inactivate metacestode vesicles (when compared to primary cells) could at least in part be due to problems in penetrating the laminated layer which surrounds the parasite cells, issues of improved tissue penetration should also be considered in studies on the development of anti-insulin signalling drugs against $\mathrm{AE}$.

\section{Conclusions}

The E. multilocularis metacestode larval stage displays a marked organ-tropism towards the mammalian host's liver where it grows infiltratively, like a malignant tumour, and where the highest concentrations of insulin within the mammalian body can be found. We herein demonstrate that mammalian insulin influences E. multilocularis larval development at physiological concentrations which, to the best of our knowledge, is also the first report on stimulatory effects of physiological insulin concentrations on any flatworm parasite. Our data indicate that E. multilocularis insulin signalling pathways, consisting of two insulin receptor-like tyrosine kinases and downstream components of the PI3K/Akt-pathway, are mediating these effects, which supports the theory that hormonal host-parasite cross-communication through evolutionarily conserved signalling systems plays an important role in Echinococcus infections. That the effects we observed in vitro are also of relevance in vivo is indicated by the fact that the metacestode stage, which grows continuously within the host liver, is not producing intrinsic insulin-like peptides for the main receptor of this stage, EmIR1, thus leaving host-derived insulin as the only relevant hormone of this class at the site of infection. Although further investigations are needed to establish a clear connection between the parasite's insulin responsiveness and the marked organ-tropism towards the host liver, we nevertheless suggest that the constantly elevated supply of insulin within the liver (when compared to serum or other organs) at least contributes to the initial development of the metacestode from parasite stem cells, and supports asexual multiplication of the metacestode. By our investigations on the inhibition of insulin signalling pathways in E. multilocularis, we also identified a lead compound that could facilitate the development of novel and effective anti-echinococcosis drugs in the future. Investigations into this direction, addressing the parasite's insulin receptor-like kinases, but also downstream components such as PI3K and Akt, are currently underway.

\section{Methods}

\section{Organisms and culture methods}

Experiments were performed with the E. multilocularis isolates H95 [32] and JAVA [45] which were continuously passaged in mongolian jirds (Meriones unguiculatus) as previously described [18]. Since we observed an influence of the period of intraperitoneal jird passages on the reproducibility of the experiments (that is, 'younger' isolates were consistently more responsive to insulin than 'old' isolates), we always used the most recent isolate that was available in the laboratory for the experiments. In vitro cultivation of metacestode vesicles under axenic conditions as well as the isolation and cultivation of primary cell cultures was carried out as previously described $[18,19]$. Protoscoleces were isolated from in vivo cultivated parasite material according to a previously established protocol [46] and were activated by pepsin/ low $\mathrm{pH}$ treatment (mimicking the transition to the definitive host) as previously described [33]. Life-dead staining of protoscoleces was carried out by incubation of protoscoleces with $0.03 \%$ methylene blue for one minute.

\section{Insulin and inhibitor treatment of parasite larvae}

Metacestode vesicles (JAVA) of a diameter of 3 to $4 \mathrm{~mm}$ were manually picked from axenic culture [19], washed in PBS and incubated in 12-well plates in the presence of conditioned medium [18]. Viability and integrity of the vesicles were measured microscopically after incubation for seven days in the presence or absence of the insulin receptor inhibitor $\operatorname{HNMPA}(\mathrm{AM})_{3} \quad$ (Enzo Life Sciences, Lörrach, Germany). Primary cells were isolated from six- month-old axenic vesicles [18] and incubated in conditioned medium supplemented with recombinant human insulin (Sigma-Aldrich, Hamburg, Germany), DMSO and $\mathrm{HNMPA}(\mathrm{AM})_{3}$. Primary cell incubation was carried out for seven days in the case of haematoxylin staining of sections. Metacestode vesicle formation from parasite stem cells was measured after three weeks of incubation by 
counting free swimming, intact vesicles and microscopic measurement of the size and amount of primary cell aggregates $[43,44]$. Protoscoleces were incubated in hepatocyteconditioned medium supplemented with insulin for three weeks (in insulin stimulation experiments) or DMSO and $\mathrm{HNMPA}(\mathrm{AM})_{3}$ for two weeks (in inhibitor experiments). Re-differentiation was evaluated by counting vesicular protoscoleces. Protoscolex viability was measured by staining with $0.03 \%$ methylene blue for one minute. All experiments were carried out independently at least three times.

\section{BrdU uptake assays}

Metacestode vesicles ( 3 to $4 \mathrm{~mm}$; JAVA) were manually picked from axenic cultures [19], washed in PBS and incubated in 12-well plates in the presence of hepatocyteconditioned medium supplemented with insulin and $1 \mathrm{mM}$ BrdU for two days. Chromosomal DNA was subsequently isolated and $500 \mathrm{ng}$ DNA was coated onto an ELISA plate using DNA coating solution (Thermo Scientific, Bonn, Germany) according to the product manual. BrdU incorporation was detected using the colorimetric BrdU ELISA kit (Roche, Mannheim, Germany). Stimulation of freshly isolated primary cells was carried out for 24 hours, followed by 4 hours of incubation with $1 \mathrm{mM}$ BrdU in a 96-well plate. For the BrdU-ELISA the colorimetric BrdU ELISA kit (Roche) was used. The lysed cells were blocked with $2 \%$ skim milk in PBS for one hour.

\section{Glucose uptake assay}

Metacestode vesicles (JAVA) were manually picked from in vitro cultures, washed in PBS and incubated overnight in (D)MEM supplemented with $0.2 \%$ FCS and $2.5 \mathrm{mM}$ glucose. Medium was changed and supplemented with $0.1 \mu \mathrm{Ci}\left[{ }^{14} \mathrm{C}\right]$-D-glucose (Hartmann Analytic, Braunschweig, Germany) to which either $10 \mathrm{nM}$ human insulin or $10 \mathrm{nM}$ insulin plus $100 \mathrm{nM} \mathrm{Na} \mathrm{VO}_{4}$ were added. Samples were incubated for one hour at $37^{\circ} \mathrm{C}$ and then washed in PBS. Vesicles were lysed with $0.15 \mathrm{M} \mathrm{NaOH}$ for five minutes at room temperature and centrifuged for one minute at 2,000 rpm. The supernatant was resuspended in UltimaGold (Perkin-Elmer, Rodgau-Juegesheim, Germany) and radioactivity was measured in a liquid scintillation counter. Data were expressed relative to control sample radioactivity.

\section{Nucleic acid isolation, cloning and sequencing}

RNA isolation from in vitro cultivated axenic metacestode vesicles (H95, JAVA), protoscoleces (JAVA) and primary cells (one week; JAVA) was performed using a Trizol (5Prime, Hamburg, Germany)-based method as previously described [43]. For reverse transcription, $2 \mu \mathrm{g}$ total RNA was used and cDNA synthesis was performed using oligonucleotide CD3-RT [46]. PCR products were cloned using the PCR Cloning Kit (QIAGEN, Hilden,
Germany) and sequenced employing an ABI prism 377 DNA sequencer (Perkin-Elmer). For cloning and sequencing the emir2 cDNA, available genomic sequences for E. multilocularis were used [22]. After partial amplification of three overlapping fragments (encoding the LBD, the intracellular portion, and the region between LBD and the transmembrane domain), cloning and sequencing, which largely confirmed the sequence as presented in GeneDB [47], the full length cDNA was amplified from metacestode mRNA preparations using the primers EmIRb-F1-dwHindIII (5'-GCT CGC AAG CTT ACA GAC AAT GAA TGT GC-3') and EmIRb-up-KpnI (5'CCT CAG GTA CCC CAT GTG AGA GAG TGG AAG TTC-3'), cloned into pSecTag2/Hydro (Life Technologies, Darmstadt, Germany), sequenced again and was used for all subsequent amplification steps. Likewise, the emilp1 and emilp2 cDNAs were full-length amplified from protoscolex mRNA preparations using primers ilp1HindIIIdw (5'-GCA TAA GCT TGT CGC CTC TGG CCC AAG-3') and ilp1NotIStop (5'-GCA TGC GGC CGC TCA GCC TTT TGC ACA-3') as well as ilp2HindIIIdw (5'-GCA TAA GCT TGG TAT CAC CTC TTC AT-3') and ilp2NotIStop (5'-GCA TGC GGC CGC CTA AAC AAC AGC ATT-3'), respectively, and cloned as described above before sequencing. All sequences as determined in this study have been deposited at the EMBL Nucleotide Sequence Database under the accession numbers [EMBL:HG326255] (emir2), [EMBL:HG326256] (emilp1), [EMBL:HG326257] (emilp2), [EMBL:HF934007] (emakt), and [EMBL:HF934006] (em4ebp).

\section{RT-PCR analysis}

Total RNA was isolated from axenically cultivated metacestode vesicles (JAVA), primary cell cultures as well as non-activated and activated protoscoleces and cDNA was produced as described previously [43]. Ten-fold, serial dilutions of normalized cDNA were then used as template for PCRs using intron-flanking, emir1-specific primers RC19 (5'- GAT GAT TCC TTC GAT TTG CA- 3') and RC21 (5' - TAA ACG AGA CGT TCC CAA CAT G - 3') as well as the intron-flanking, emir2-specific primers EmIRbdw3 (5'-GGA CGA GTG GGA GGT GG-3') and EmIRbup3 (5'-GAA CTG TTT CAT GTG GGA GG-3'). The PCR program was $94^{\circ} \mathrm{C}$ for one minute, $59^{\circ} \mathrm{C}$ for 30 seconds and $72^{\circ} \mathrm{C}$ for 30 seconds at 35 cycles. The constitutively expressed control gene elp [46] was amplified using intron-flanking primers Em1015 (5' - AAT AAG GTC AGG GTG ACT AC -3') and Em10-16 (5' - TTG CTG GTA ATC AGT CGA TC -3') using the PCR program $94^{\circ} \mathrm{C}$ for one minute, $53^{\circ} \mathrm{C}$ for 30 seconds and $72^{\circ} \mathrm{C}$ for 30 seconds at 35 cycles. PCR products were separated on a $1 \%$ agarose gel and stained with ethidium bromide. 


\section{Generation of anti-EmIR1 and anti-EmIR2 immune sera}

Antibodies were raised against the intracellular domain of EmIR1 (M1129- C1749) [10]. The respective cDNA regions were amplified using primers CK5 (5'- ATC GCT GGA TCC ATA CAT CGC ATT CGA AAG AA -3') and CK6 (5'- AAC ACA AGA TCT TGA ACA AGA CGA CCC ATC ACC GTC A -3'). The PCR product was ligated into the $\mathrm{pBAD} /$ Thio-Topo $^{\circ}$ vector (pBAD $/ \mathrm{TOPO}^{\circ}$ ThioFusion $^{\mathrm{Ts}}$ Expression Kit, Invitrogen, Karlsruhe, Germany) and expressed and purified according to the manufacturer's instructions. Immunisation of a rabbit with the purified protein was performed by Immunoglobe (Himmelstadt, Germany) using program PRO-10 W-STD [48]. Likewise, nt sequences encoding the intracellular region of EmIR2 were amplified using primers emirbF3dw (5'-GCA ACC ACC TTC GCT AAT G-3') and emir2-intra-up (5'-CTC AGA ATT CAT GTG AGA GTG GAA G-3') and cloned into the pBAD/ TOPO ThioFusion expression plasmid (Invitrogen). The EmIR2-Thio construct was expressed in Escherichia coli as described above for EmIR1 and the protein was purified via the His-tag. Elution fractions were dialysed and used for rabbit immunisation according to the procedure described above. In subsequent western blot analyses the purified immune-serum only detected EmIR2-Thio and EmIR2-GST, but not EmIR1-GST [see Additional file 4], thus confirming specificity.

\section{SDS -PAGE and Western Blot analysis}

Lysates of axenically cultivated metacestode vesicles (JAVA, H95) were obtained by mechanically disrupting the cysts and centrifugation for five minutes at $800 \mathrm{~g}$ and $4{ }^{\circ} \mathrm{C}$. The pellet was then lysed with lysis buffer (20 mM Tris- $\mathrm{HCl}, \mathrm{pH} 8.0 ; 150 \mathrm{mM} \mathrm{NaCl} ; 1 \mathrm{mM}$ ethylenediaminetetraacetic acid (EDTA) $\mathrm{pH}$ 8.0; 1\% Triton $\mathrm{X}-100 ; 2 \%$ sodium deoxycholate; $1 \mathrm{mM} \mathrm{Na} \mathrm{VO}_{4} ; 10 \mathrm{mM}$ $\mathrm{NaF}$ ) supplemented with $1 \times$ protease inhibitor (Complete Protease Inhibitor Cocktail Tablets, Roche) for one to two hours at $4^{\circ} \mathrm{C}$ under constant rotation. The protein concentration of the samples was determined and equal amounts of protein were loaded onto a 10\% SDS gel. Primary cells, non-activated and activated protoscoleces were centrifuged for five minutes at $800 \mathrm{~g}$ and $4^{\circ} \mathrm{C}$ and lysed with lysis buffer for one to two hours at $4^{\circ} \mathrm{C}$ under constant rotation. Proteins were subsequently separated (10\% SDS-PAGE), transferred to a membrane and detected with antibodies. The following antibodies were used: anti-EmIR1 (1:1,000), anti-EmIR2 (1:1,000), and anti-rabbit immunoglobulin G-horseradish peroxidase (IgG-HRP) (1:5,000; Jackson, Immuno Research, West Grove, PA, USA) as secondary antibody. For the $\beta$-actin control, a rabbit anti- $\beta$-actin antibody (Cell Signalling, Frankfurt/Main, Germany; $1: 1,000)$ was used.

\section{Immunohistochemistry and electron microscopy}

For conventional transmission electron microscopy (TEM) and increased preservation of carbohydrate based structures, such as glycogen, in vitro cultured E. multilocularis metacestodes were fixed in $100 \mathrm{mM}$ sodium cacodylate buffer, pH 6.8, containing $2.5 \%$ glutaraldehyde and $0.1 \%$ tannic acid for four hours at room temperature [49]. After three washes in cacodylate buffer and postfixation in $2 \%$ osmium tetroxide in cacodylate buffer for two hours at room temperature, specimens were prestained in 1\% uranyle acetate for 30 minutes at room temperature. After washing in water, samples were dehydrated in a stepwise gradient of ethanol (30, 50, 70, 90, $3 \times 100 \%)$ and were embedded in Epon 812 epoxy resin (Sigma), with three changes of resin within 48 hours. Blocks were polymerized at $60^{\circ} \mathrm{C}$ for 24 hours.

Immunofluorescence and immunogold-TEM employing the anti-EmIR1 antiserum or a general anti-Echinococcus metacestode antigen antibody [50] were done on sections obtained from metacestodes embedded in acrylic LRWhite resin (Sigma). To this end, in vitro cultured metacestodes were washed twice with PBS and then placed in fixation solution (3\% paraformaldehyde $/ 0.05 \%$ glutaraldehyde in $100 \mathrm{mM}$ sodium cacodylate buffer ( $\mathrm{pH}$ 6.8)) for 30 minutes at room temperature, washed in sodium cacodylate buffer and placed into $20 \mathrm{mM}$ glycine in PBS for 30 minutes on ice. They were dehydrated in steps of 30 , 50, 70, 90 and $100 \%$ ethanol on ice, followed by two changes of LR-White resin. Specimens were infiltrated at $-20^{\circ} \mathrm{C}$ for 24 hours and, subsequently, the resin was changed again. Polymerization of the resin was done at $60^{\circ} \mathrm{C}$ for 24 hours under exclusion of $\mathrm{O}_{2}$ and tissue blocks were stored at $4^{\circ} \mathrm{C}$ until use.

Sections of $1 \mu \mathrm{m}$ thickness for immunofluorescence and $80 \mathrm{~nm}$ thickness for conventional or immunogold TEM were cut on a Reichert and Jung ultramicrotome (Vienna, Austria). For immunofluorescence, sections were mounted onto poly-l-Lysine coated glass coverslips. For TEM, sections were placed onto formvar-carbon coated grids.

For immunofluorescence staining, glass coverslips were placed into blocking buffer (PBS, 3\% BSA) for one hour and were then incubated with anti-EmIR1 antiserum, diluted 1:250 in PBS, 0.3\% BSA for one hour at room temperature. Secondary antibodies were goat antirabbit FITC (fluorescein isothiocyanate; Sigma, Buchs, Switzerland) diluted 1:200 and applied for 30 minutes. The coverslips were then finally washed for 10 minutes in PBS and were mounted on glass slides with VECTASHIELD ${ }^{\circ}$ Mounting Medium containing DAPI (4',6-diamidino-2phenylindol; Vector Laboratories, Burlingame, CA, USA). Slides were observed on a Nikon Eclipse ${ }^{\odot}$ E800i digital confocal fluorescence microscope (Nikon Precision Inc. Belmont, CA, USA) and processing of images was 
performed using the Openlab 2.0.7 software (Improvision, Waltham, MA, USA).

For immunogold TEM, grids were placed onto drops of blocking solution for one hour, and were then incubated on anti-EmIR1 antiserum as for immunofluorescence. Secondary antibody-gold conjugates were 10 nm-gold-goat anti-rabbit conjugates (Aurion, Wageningen, NL), diluted 1:10 in PBS, 0.3\% BSA, and were applied for one hour, followed by three washes in PBS, five minutes each. Grids were briefly dipped into distilled water and air dried. Contrasting of both conventional and immunogold TEM samples was done with uranyle acetate and lead citrate. Specimens were viewed on a Phillips 400 TEM operating at $80 \mathrm{kV}$.

For immune-histochemistry using the anti-EmIR2 antiserum, samples were embedded in Technovit 8100 (Heraeus Kulzer, Wehrheim, Germany) and $4 \mu \mathrm{m}$ sections were taken on glass slides. Sections were dried for two hours at $37^{\circ} \mathrm{C}$ and cauterise for four minutes with acetone. Rehydration was performed by incubation for five minutes in $100 \%$ ethanol, five minutes in $96 \%$ ethanol, five minutes in $70 \%$ ethanol and five minutes in $1 \mathrm{x}$ PBS. Samples were then permeabilised for seven minutes with $1 \%$ Triton $\mathrm{X}-100$ in PBS and rinsed three times with PBS. For blocking endogenous peroxidases, slides were incubated for 10 minutes with $0.3 \% \quad \mathrm{H}_{2} \mathrm{O}_{2}$ in methanol and washed two times for 10 minutes with PBS. The first antibody (anti-EmIR2, 1:10 in blocking buffer) was added and incubation was performed overnight at $4^{\circ} \mathrm{C}$ (humid chamber). Samples were then washed three times for five minutes with PBS and the second antibody (POX-anti-rabbit, 1:50 in blocking buffer) was incubated for three hours at room temperature in a humid chamber. Samples were washed again, substrate solution (2 mg diaminobenzidine (DAB); $2 \mathrm{ml} \mathrm{PBS;} 2 \mathrm{ml} \mathrm{H}_{2} 0 ; 1.34 \mu \mathrm{l} 30 \%$ $\mathrm{H}_{2} \mathrm{O}_{2}$ ) was added and incubated at room temperature until the reaction was stopped by rinsing in $\mathrm{H}_{2} \mathrm{O}$. Counterstaining with haemotoxylin was carried out by incubation for six minutes with Haemalaun (Roche). Slides were washed and passed through an increasing ethanol series (five minutes in $70 \%$ ethanol, five minutes in $96 \%$ ethanol, five minutes in $100 \%$ ethanol; five minutes in xylol) and mounted with Entellan (Merck, Darmstadt, Germany). As a control, staining of parasite sections with only the secondary antibody (POX-anti-rabbit) was performed and continuously yielded negative results.

\section{In vitro phosphorylation of parasite proteins EmIR1 phosphorylation in membrane fractions}

An assay adopted from Vicogne et al. [41] was used. In vitro cultivated metacestode vesicles (H95) were isolated and incubated in (D)MEM 0.2\% FCS (supplemented with $10 \mathrm{U} / \mathrm{ml}$ penicillin G/streptomycin, $100 \mu \mathrm{M}$ L-cysteine, $10 \mu \mathrm{M}$ bathocuproinedisulphonic acid, $0.01 \% \beta$ - mercaptoethanol) for 24 hours at $37^{\circ} \mathrm{C}$ and $5 \% \mathrm{CO}_{2}$. After this incubation period, vesicles were washed ( $1 \mathrm{x}$ PBS) and transferred into a $15 \mathrm{ml}$ Falcon tube. Excess PBS was removed and $0.5 \mathrm{ml}$ homogenization buffer (20 mM Tris- $\mathrm{HCl}, \mathrm{pH} 7.5 ; 150 \mathrm{mM} \mathrm{NaCl} ; 1$ mM EDTA pH 8.0; $1 \%$ Triton X-100; $1 \mathrm{mM} \mathrm{Na} \mathrm{VO}_{4} ; 10 \mathrm{mM} \mathrm{NaF}$; $1 \mathrm{mM}$ phenylmethanesulphonyl fluoride (PMSF); $10 \mu \mathrm{g} /$ $\mathrm{ml}$ apronitin A; $1 \mu \mathrm{g} / \mathrm{ml}$ Pepstatin A; $1 \mu \mathrm{M}$ leupeptin hemisulphate) were added per $1 \mathrm{ml}$ intact vesicles. The vesicles were mechanically homogenized at $4^{\circ} \mathrm{C}$ before the membrane fraction was pelleted by centrifugation $\left(3,000 \mathrm{rpm}\right.$, three minutes) at $4^{\circ} \mathrm{C}$. Supernatant was discarded and the pellet was resuspended in fresh homogenization buffer. The suspension was aliquoted into reaction tubes and either human insulin (Hoechst; $100 \mathrm{nM}$ - saturating concentration to ensure maximal activation [25-30]) or human IGF (Immunotools, Friesoythe, Germany; $100 \mathrm{nM}$ ) were added. After 10 minutes at $37^{\circ} \mathrm{C}$, the membrane fraction was pelleted again $(3,000 \mathrm{rpm}$, three minutes at room temperature) and resuspended in $300 \mu \mathrm{l}$ kinase buffer (50 mM Tris- $\mathrm{HCl} \mathrm{pH} 7.5 ; 2 \mathrm{mM} \mathrm{MnCl}_{2}$; $15 \mathrm{mM} \mathrm{MgCl}_{2} ; 0.1 \%$ Triton X-100; $1 \mathrm{mM} \mathrm{Na}_{3} \mathrm{VO}_{4} ; 10 \mathrm{mM}$ $\mathrm{NaF} ; 1 \mathrm{mM}$ PMSF; $10 \mu \mathrm{g} / \mathrm{ml}$ apronitin; $1 \mu \mathrm{g} / \mathrm{ml}$ Pepstatin A, $1 \mu \mathrm{M}$ leupeptin hemisulphate) containing $100 \mu \mathrm{M}$ $\mathrm{HNMPA}(\mathrm{AM})_{3}$ or an equal volume of DMSO. After $30 \mathrm{mi}-$ nutes at $37^{\circ} \mathrm{C}$, the kinase buffer was supplemented with $50 \mu \mathrm{M}\left[{ }^{32} \mathrm{P}\right] \gamma$-ATP $(4.4 \mathrm{ml}$ of $110 \mathrm{TBq} / \mathrm{mmol})$ and phosphorylation was carried out for 40 minutes at $30^{\circ} \mathrm{C}$. The membrane fraction was then briefly centrifuged (five minutes, 1,300 rpm at room temperature), the supernatant was discarded, and the pellet was resuspended in $1 \mathrm{ml}$ lysis buffer (20 mM Tris- $\mathrm{HCl}$ pH 8.0; $150 \mathrm{mM} \mathrm{NaCl} ; 1 \mathrm{mM}$ EDTA pH 8.0; 1\% Triton X-100; 2\% sodium deoxycholate; $1 \mathrm{mM} \mathrm{Na} \mathrm{VO}_{4} ; 10 \mathrm{mM} \mathrm{NaF} ; 1 \mathrm{mM}$ PMSF; $10 \mu \mathrm{g} / \mathrm{ml}$ apronitin; $1 \mu \mathrm{g} / \mathrm{ml}$ Pepstatin A; $1 \mu \mathrm{M}$ leupeptin hemisulphate). To solubilise membrane bound proteins, samples were gently agitated at $4^{\circ} \mathrm{C}$ for one hour. Insoluble material was removed by centrifugation (five minutes, 1,300 rpm at room temperature) and the EmIR1 $\beta$-subunit was immunoprecipitated from the supernatant using the anti-EmIR1 antiserum (1:100) employing agarose G-beads (Upstate, Lake Placid, NY, USA) according to the manufacturer's instructions. Phosphorylation of immunoprecipitated proteins was subsequently analysed by SDS-PAGE ( $8 \%$ polyacrylamide (PAA)), followed by transfer onto a nitrocellulose membrane and autoradiography (X-ray film; Fuji).

\section{EmIR1 phosphorylation in intact vesicles}

Intact in vitro cultivated metacestode vesicles (H95) were manually picked, transferred into Falcon tubes and incubated in (D)MEM $(0.2 \%$ FCS $)$ in the presence or absence of $100 \mathrm{nM}$ insulin (saturating concentration to ensure maximal activation [25-30]). After 10 minutes incubation, medium was removed and the metacestode 
vesicles were mechanically disrupted and pelleted by centrifugation (one minute, 1,300 rpm, $4^{\circ} \mathrm{C}$ ). The pellet was resuspended in $1 \mathrm{ml}$ lysis buffer (see above), agitated for one hour at $4^{\circ} \mathrm{C}$ and insoluble material was removed by centrifugation ( 15 minutes, $1,300 \mathrm{rpm}, 4^{\circ} \mathrm{C}$ ). Immunoprecipitation of EmIR1 using the anti-EmIR1 antiserum was carried out as described above and precipitated proteins were analysed by Western blotting with the antiEmIR1 antiserum. Tyrosine phosphorylation of the EmIR1 $\beta$-subunit was carried out using an anti-phospho-tyrosine antibody (P-Tyr 100, Cell Signalling).

\section{Phosphorylation of components of the PI3K/Akt paythway} Intact in vitro cultivated metacestode vesicles (JAVA) were incubated for 16 hours in (D)MEM (0.2\% FCS), followed by stimulation with $10 \mathrm{nM}$ insulin for 5,30 and 60 minutes. In some experiments, $\mathrm{HNMPA}(\mathrm{AM})_{3}$ or the PI3K inhibitor LY294002 [51] (both at $100 \mu \mathrm{M}$ ) were added two hours prior to insulin stimulation. Samples were then put on ice and washed once with cold PBS supplemented with $1 \mathrm{mM} \mathrm{Na}_{3} \mathrm{VO}_{4}$ and $10 \mathrm{mM} \mathrm{NaF}$. Vesicles were then mechanically disrupted and hydatid fluid was removed after centrifugation (three minutes, $\left.800 \mathrm{~g}, 4^{\circ} \mathrm{C}\right)$. Crude lysates were then produced by adding 5 x sample buffer (15\% Tris- $\mathrm{HCl}$ pH $6.8 ; 50 \%$ glycerol; $10 \%$ SDS; $25 \% \beta$-meracptoethanol) to a final concentration of $1 \mathrm{x}$. Samples were then boiled for 10 minutes and centrifuged for one minute at 11,000 g. The supernatant was separated by SDS-PAGE and Western blot analysis was carried out using the following antibodies: antiphospho-4E-BP1 (T37/46) (Cell Signaling, Frankfurt, Germany), and anti-phospho-Akt Substrate (RXRXXS/T) (Cell Signaling). For secondary antibodies anti-mouse IgGHRP (1:10000; Jackson, Immuno Research) and anti-rabbit IgG-HRP (1:5000; Jackson, Immuno Research) were used.

\section{Yeast two-hybrid analyses}

The Gal4-based MATCHMAKER system (Clontech, Mountain View, CA, USA) was used essentially as described previously $[10,11,13]$. Constructs for the fusion of the EmIR1- and HIR- LBDs to the Gal4 activation domain (AD) as well as human pro-insulin to the Gal4 DNA binding domain (BD) have been described previously [10]. For fusing the EmIR2 LBD with the Gal4 AD, the respective cDNA sequences were amplified using primers emir2ex-EcoRI (5'-GTC ACG AAT TCA CAG ACA ATG AAT GTG C-3') and emir2ex-XhoI (5'-GTT GAC TCG AGG TCC TTC ACA GAA GC-3') and were cloned into vector pGADT7 using restriction sites incorporated into the primer sequences. For fusions of the Echinococcus ILPs with the Gal4 BD, corresponding cDNA sequences were amplified using primers emilp1EcoRI (5'-GTC ACG AAT TCT TTG AGA TGG ATA AAA CG-3') and emilp1BamHI (5'-GCG ATG GAT
CCG CCT TTT GCA CAG AAC-3') (for emilp1) as well as emilp2EcoRI (5'-GTC ACG AAT TCG TAT CAC CTC TTC ATG-3') and emilp2BamHI (5'-GCG ATG GAT CCA ACA ACA GCA TTG AG-3') (for emilp2) and cloned into plasmid pGBKT7 via restriction sites incorporated into the primer sequences. All constructs were checked by sequencing for correct reading frames. Co-transformation of the plasmid constructs into yeast and growth analysis was performed essentially as previously described [10]. As controls, empty vectors and fusion proteins with the E. multilocularis protein Elp (Ezrin-radixin-Moesin-like protein [52]) were used as previously described [11].

\section{EdU labeling and detection}

A total of $50 \mu \mathrm{M}$ EdU (Life Technologies) was added to metacestode in vitro cultures (JAVA) and incubated for five hours. For fixation, metacestode vesicles were gently opened using a syringe tip to allow entry of the fixative and detection reagents. The samples were fixed for one hour at room temperature in $4 \%$ paraformaldehyde prepared in PBS (PFA-PBS). Detection was performed with the Click-iT ${ }^{\oplus}$ EdU Alexa Fluor 555 Imaging Kit (Abcam, Cambridge, UK) as described by the manufacturer for sections, but with a modified protocol in which all steps were doubled in length and the washes were increased in number. EdU detection was performed after carrying out the in situ hybridization protocol. Finally, samples were co-stained with DAPI.

\section{Whole-mount in situ hybridization (WMISH)}

Digoxigenin-labeled probes were synthesised by in vitro transcription with T7 and SP6 polymerases (New England Biolabs, Frankfurt/Main, Germany), using the DIG RNA labeling mix (Roche, Mannheim, Germany) as described by the manufacturer from an emir2 cDNA fragment cloned into pDrive using the Qiagen PCR cloning system. Primers used for amplification of the probe were emir2-dw2 (5'ACA GAC AAT GAA TGT GCT TCC C-3') and emir2up5 (5'-CCA TTC GTA AAA ACC AGC GC-3'), which encompass an approximately $3 \mathrm{~kb}$ fragment of the emir2 cDNA region encoding the extracellular portion of the receptor.

The WMISH protocol was adapted from methodology described in [53] and a detailed protocol will be published elsewhere (Koziol et al., submitted for publication).

\section{Computer analyses}

Amino acid comparisons were performed using BLAST on the nr-aa database collection available under [54]. Genomic analyses and BLAST searches against the final assembly version of the E. multilocularis genome [22] were done using the respective resources of the Sanger Institute (Hinxton, UK) [47]. 


\section{Ethical approval}

All experiments were carried out in accordance with European and German regulations on the protection of animals (Tierschutzgesetz). Ethical approval of the study was obtained from the local ethics committee of the government of Lower Franconia (55.2-2531.01-31/10).

\section{Additional files}

\section{Additional file 1: The Echinococcus multilocularis life cycle.}

Schematic representation of the E. multilocularis life cycle and suggested actions of host insulin on parasite development/physiology.

Additional file 2: Amino acid sequence comparisons between Echinococcus and human insulin receptors. Pileups of LBDs and TKDs of insulin receptors from Echinococcus and human origin.

Additional file 3: Gene expression profiles of Echinococcus insulin signalling components during the life cycle. Diagram displaying transcriptome data concerning the expression of emir1, emir2, emilp1, and emilp2 in larval and adult stages.

Additional file 4: Testing the anti-EmIR1 and anti-EmIR2 antisera. File showing Western blot and immunoprecipitation analyses concerning EmIR1 and EmIR2 using the generated antisera.

Additional file 5: In silico analyses. Figure showing in silico models for the binding of HNMPA(AM)3 to the TKD of EmIR1.

Additional file 6: Components of the $E$. multilocularis insulin signalling pathways. Table with E. multilocularis genes predicted to be involved in insulin signalling pathways according to the E. multilocularis genome sequencing project.

Additional file 7: Amino acid sequence comparison of PKB components from different organisms. File showing sequence alignment of the E. multilocularis PKB-homolog EmAkt with PKBs from human and Drosophila origin.

Additional file 8: Amino acid sequence comparison of 4E-BP orthologs from different origin. File showing sequence alignment of the E. multilocularis $4 \mathrm{E}-\mathrm{BP}$ ortholog with those of human and insect origin.

\section{Abbreviations}

4E-BP: eukaryotic translation initiation factor 4E-binding protein; AD: activation domain; AE: alveolar echinococcosis; BD: binding domain; BLAST: Basic Local Alignment Search Tool; BrdU: bromodeoxyuridine: BSA: bovine serum albumin; CDD: conserved domain database; DAPI: 4',6diamidino-2-phenylindole; (D)MEM: (Dulbecco's) modified Eagle's medium; DMSO: dimethylsulphoxide; EDTA: ethylenediaminetetraacetic acid; EdU: 5-ethylnyl-2'-deoxyuridine; EGF: epidermal growth factor; ELISA: enzymelinked immuosorbent assay; ERK: extracellular signal regulated kinase; FCS: fetal calf serum; GSC: glycogen storage cell; HIR: human insulin receptor; HNMPA: 2-hydroxynaphthalen-1-yl-methylphosphonic acid; HRP: horseradish peroxidase; IGF: insulin-like growth factor; IgG: immunoglobulin G; ILP: insulin-like peptide; IRS: insulin receptor substrate; LBD: ligand binding domain; MAPK: mitogen-activated protein kinase; PBS: phosphate-buffered saline; PI3K: phosphatidyl-inositol-3-phosphate kinase; PKB: protein kinase B; PMSF: phenylmethanesulphonyl fluoride; SMART: Simple Modular Architecture Research Tool; TEM: transmission electron microscopy; TGF: transforming growth factor; TKD: tyrosine kinase domain; WMISH: whole mount in situ hybridization.

\section{Competing interests}

The authors declare that they have no competing interests.

\section{Authors' contributions}

The study was conceived by $\mathrm{KB}$ with contributions from TD and $\mathrm{AH}$. The experiments were designed by $\mathrm{KB}, \mathrm{TD}$, and $\mathrm{AH}$. The experiments were performed and analysed by SH, CK, UK, DS, MS, SF, BS and VG. Method development was carried out by UK, SH, CK, DS, MS, and AH. The manuscript was written by KB with contributions from TD, AH and UK. All authors have read and approved the final manuscript.

\section{Acknowledgements}

This work was supported by grants of the Deutsche

Forschungsgemeinschaft (DFG) (Grants IRTG 1522 and BR 2045/4-1) as well as the Wellhöfer Foundation (all to KB). We wish to thank Monika Bergmann and Dirk Radloff for excellent technical assistance. Sequence data of the $E$. multilocularis genome sequencing project have been produced by the Parasite Sequencing Unit at the Wellcome Trust Sanger Institute (Matthew Berriman) [47]. This publication was funded by the German Research Foundation (DFG) and the University of Würzburg in the funding programme Open Access Publishing.

\section{Author details}

${ }^{1}$ University of Würzburg, Institute of Hygiene and Microbiology, Josef-Schneider-Strasse 2, D-97080 Würzburg, Germany. 'Department of Bioinformatics, University of Würzburg, Biocenter am Hubland, D-97074 Würzburg, Germany. ${ }^{3}$ Institute of Parasitology, Vetsuisse Faculty, University of Berne, Länggass-Strasse 122, CH-3012 Bern, Switzerland.

Received: 18 November 2013 Accepted: 21 January 2014

Published: 27 January 2014

\section{References}

1. Kern P: Clinical features and treatment of alveolar echinococcosis. Curr Opin Infect Dis 2010, 23:505-512.

2. Brehm K: Echinococcus multilocularis as an experimental model in stem cell research and molecular host-parasite interaction. Parasitology 2010, 137:537-555.

3. Smyth JD, Howkins AB, Barton M: Factors controlling the differentiation of the hydatid organism, Echinococcus granulosus, into cystic or strobilar stages in vitro. Nature 1966, 211:1374-1377.

4. Shojaee-Moradie F, Powrie JK, Sundermann E, Spring MW, Schüttler A, Sönksen PH, Brandenburg D, Jones RH: Novel hepatoselective insulin analog: studies with a covalently linked thyroxyl-insulin complex in humans. Diabetes Care 2000, 23:1124-1129.

5. Misbin Rl, Merimee TJ, Lowenstein JM: Insulin removal by isolated perfused rat liver. Am J Physiol 1976, 230:171-177.

6. Song SH, Mclntyre SS, Shah H, Veldhuis JD, Hayes PC, Butler PC: Direct measurement of pulsatile insulin secretion from the portal vein in human subjects. J Clin Endocrinol Metab 2000, 85:4491-4499.

7. Siddle K: Signalling by insulin and IGF receptors: supporting acts and new players. J Mol Endocrinol 2011, 47:R1-R10.

8. Telemann AA: Molecular mechanisms of metabolic regulation by insulin in Drosophila. Biochem J 2010, 425:13-26.

9. Kaletsky R, Murphy CT: The role of insulin/IGF-like signaling in C. elegans longevity and aging. Dis Model Mech 2010, 3:415-419.

10. Konrad C, Kroner A, Spiliotis M, Zavala-Góngora R, Brehm K: Identification and molecular characterisation of a gene encoding a member of the insulin receptor family in Echinococcus multilocularis. Int J Parasitol 2003, 33:301-312.

11. Khayath N, Vicogne J, Ahier A, BenYounes A, Konrad C, Trolet J, Viscogliosi E, Brehm K, Dissous C: Diversification of the insulin receptor family in the helminth parasite Schistosoma mansoni. FEBS J 2007, 274:659-676.

12. Ahier A, Khayath N, Vicogne J, Dissous C: Insulin receptors and glucose uptake in the human parasite Schistosoma mansoni. Parasite 2008 15:573-579.

13. You H, Zhang W, Jones MK, Gobert GN, Mulvenna J, Rees G, Spanevello M, Blair D, Duke M, Brehm K, McManus DP: Cloning and characterisation of Schistosoma japonicum insulin receptors. PLOS One 2010, 5:e9868.

14. Escobedo G, Romano MC, Morales-Montor J: Differential in vitro effects of insulin on Taenia crassiceps and Taenia solium cysticerci. J Helminthol 2009, 83:403-412.

15. Canclini L, Esteves A: In vivo response of Mesocestoides vogae to human insulin. Parasitology 2009, 136:203-209.

16. Miller CM, Newmark PA: An insulin-like peptide regulates size and adult stem cells in planarians. Int J Dev Biol 2012, 56:75-82.

17. Brehm K, Spiliotis M: Recent advances in the in vitro cultivation and genetic manipulation of Echinococcus multilocularis metacestodes and germinal cells. Exp Parasitol 2008, 119:506-515. 
18. Spiliotis M, Brehm K: Axenic in vitro cultivation of Echinococcus multilocularis metacestode vesicles and the generation of primary cell cultures. Methods Mol Biol 2009, 470:245-262.

19. Spiliotis M, Lechner S, Tappe D, Scheller C, Krohne G, Brehm K: Transient transfection of Echinococcus multilocularis primary cells and complete in vitro regeneration of metacestode vesicles. Int J Parasitol 2008, 38:1025-1039

20. Olson PD, Zarowiecki M, Kiss F, Brehm K: Cestode genomics - progress and prospects for advancing basic and applied aspects of flatworm biology. Parasite Immunol 2012, 34:130-150.

21. al Nahhas S, Gabrion C, Walbaum S, Petavy AF: In vivo cultivation of Echinococcus multilocularis protoscoleces in micropore chambers. Int J Parasitol 1991, 21:383-386.

22. Tsai IJ, Zarowiecki M, Holroyd N, Garciarrubio A, Sanchez-Flores A, Brooks KL, Tracey A, Bobes RJ, Fragoso G, Sciutto E, Aslett M, Beasley H, Bennett HM, Cai J, Camicia F, Clark R, Cucher M, De Silva N, Day TA, Deplazes P, Estrada K, Fernández C, Holland PW, Hou J, Hu S, Huckvale T, Hung SS, Kamenetzky L, Keane JA, Kiss $F$, et al: The genomes of four tapeworm species reveal adaptations to parasitism. Nature 2013, 496:57-63.

23. Hwang JB, Frost SC: Effect of alternative glycosylation on insulin receptor processing. J Biol Chem 1999, 274:22813-22820.

24. Monteiro KM, de Carvalho MO, Zaha A, Ferreira HB: Proteomic analysis of the Echinococcus granulosus metacestode during infection of its intermediate host. Proteomics 2010, 10:1985-1999.

25. White MF, Shoelson SE, Keutmann H, Kahn CR: A cascade of tyrosine autophoshorylation in the $\beta$-subunit activates the phosphotransferase of the insulin receptor. J Biol Chem 1988, 263:2969-2980.

26. Saad MJ, Folli F, Araki E, Hashimoto N, Csermely P, Kahn CR: Regulation of insulin receptor, insulin receptor substrate-1 and phosphatidylinpsitol 3-kinase in 3 T3-F442A adipocytes. Effects of differentiation, insulin, and dexamethasone. Mol Endocrinol 1994, 8:545-557.

27. Cheatham B, Shoelson SE, Yamada K, Goncalves E, Kahn CR: Substitution of the erbB-2 oncoprotein transmembrane domain activates the insulin receptor and modulates the action of insulin and insulin receptor substrate 1. Proc Natl Acad Sci U S A 1993, 90:7336-7340.

28. Zhande R, Mizchell JJ, Wu J, Sun XJ: Molecular mechanism of insulin-induced degradation of insulin receptor substrate 1. Mol Cell Biol 2002, 22:1016-1026.

29. Blanquart C, Gonzalez-Yanes C, Issad T: Monitoring the activation state of insulin/insulin-like growth factor-1 hybrid receptors using bioluminescence resonance engery transfer. Mol Pharmacol 2006, 70:1802-1811.

30. Assmann A, Ueki K, Winnay JN, Kadowaki T, Kulkarni RN: Glucose effects on beta-cell growth and survival require activation of insulin receptors and insulin receptor substrate 2. Mol Cell Biol 2009, 29:3219-3228.

31. Vanderstraete M, Gouignard N, Cailliau K, Morel M, Lancelot J, Bodart JF, Dissous C: Dual targeting of insulin and venus kinase receptors of Schistosoma mansoni for novel anti-schistosome therapy. PLoS Negl Trop Dis 2013, 7:e2226.

32. Spiliotis M, Konrad C, Gelmedin V, Tappe D, Brückner S, Mösch HU, Brehm K: Characterization of EmMPK1, an ERK-like MAP kinase from Echinococcus multilocularis which is activated in response to human epidermal growth factor. Int J Parasitol 2006, 36:1097-1112.

33. Gelmedin V, Spiliotis M, Brehm K: Molecular characterisation of MEK1/2- and MKK3/6-like mitogen-activated protein kinase kinases (MAPKK) from the fox tapeworm Echinococcus multilocularis. Int J Parasitol 2009, 40:555-567.

34. Horwitz DL, Starr Jl, Mako ME, Blackard WG, Rubenstein AH: Proinsulin, insulin, and C-peptide concentrations in human portal and peripheral blood. J Clin Invest 1975, 55:1278-1283.

35. Balks HJ, Jungermann K: Regulation of peripheral insulin/glucagon levels by rat liver. Eur J Biochem 1984, 141:645-650.

36. Vuitton DA, Gottstein B: Echinococcus multilocularis and its intermediate host: a model of parasite-host interplay. J Biomed Biotechnol 2010, 2010:923193.

37. Beall MJ, Pearce E: Transforming growth factor- $\beta$ and insulin-like signalling pathways in parasitic helminths. Int J Parasitol 2002, 32:399-404

38. LoVerde PT, Osman A, Hinck A: Schistosoma mansoni: TGF- $\beta$ signalling pathways. Exp Parasitol 2007, 117:304-317.

39. Brehm K: The role of evolutionarily conserved signalling systems in Echinococcus multilocularis development and host-parasite interaction. Med Microbiol Immunol 2010, 199:247-259.

40. Zavala-Gongora R, Kroner A, Bernthaler P, Knaus P, Brehm K: A member of the transforming growth factor- $\beta$ receptor family from Echinococcus multilocularis is activated by human bone morphogenetic protein 2 . Mol Biochem Parasitol 2006, 146:265-271.

41. Vicogne J, Cailliau K, Tulasne D, Browaeys E, Yan YT, Fafeur V, Vilain JP, Legrand D, Trolet J, Dissous C: Conservation of epidermal growth factor receptor function in the human parasitic helminth Schistosoma mansoni. J Biol Chem 2004, 279:37407-37414.

42. Hemmings BA, Restuccia DF: PI3K-PKB/Akt pathway. Cold Spring Harb Perspect Biol 2012, 4:a011189.

43. Gelmedin V, Caballero-Gamiz R, Brehm K: Characterization and inhibition of a p38-like mitogen-activated protein kinase (MAPK) from Echinococcus multilocularis: antiparasitic activities of p38 MAPK inhibitors. Biochem Pharmacol 2008, 76:1068-1081.

44. Hemer S, Brehm K: In vitro efficacy of the anticancer drug imatinib on Echinococcus multilocularis larvae. Int J Antimicrob Agents 2012, 40:458-462.

45. Tappe D, Brehm K, Frosch M, Blankenburg A, Schrod A, Kaup FJ, Mätz-Rensing K: Echinococcus multilocularis infection of several Old World monkey species in a breeding enclosure. Am J Trop Med Hyg 2007, 77:504-506.

46. Brehm K, Wolf M, Beland $H$, Kroner A, Frosch M: Analysis of differential gene expression in Echinococcus multilocularis larval stages by means of spliced leader differential display. Int J Parasitol 2003, 33:1145-1159.

47. The Echinococcus multilocularis Homepage on GeneDB. [http://www. genedb.org/Homepage/Emultilocularis]

48. immunoGlobe ${ }^{\circledast}$ Antikörpertechnik GmbH. [http://www.immunoglobe. com/home.html]

49. Ingold K, Gottstein B, Hemphill A: High molecular mass glycans are major structural elements associated with the laminated layer of in vitro cultivated Echinococcus multilocularis metacestodes. Int J Parasitol 2000, 30:207-214.

50. Ingold K, Dai W, Rausch RL, Gottstein B, Hemphill A: Characterization of the laminated layer of in vitro cultivated Echinococcus vogeli metacestodes. J Parasitol 2001, 87:55-64.

51. Kong D, Yamori T: Phosphatidylinositol 3-kinase inhibitors: promising drug candidates for cancer therapy. Cancer Sci 2008, 99:1734-1740.

52. Brehm $K$, Jensen $K$, Frosch $P$, Frosch M: Characterization of the genomic locus expressing the ERM-like protein of Echinococcus multilocularis. Mol Biochem Parasitol 1999, 100:147-152.

53. Olson Lab: NHM London, Whole Mount in situ Hybridization. Available at: http://www.olsonlab.com/resources/Data-Files/WMISH-OlsonLab.pdf.

54. GenomeNet Database Resources. [http://www.genome.jp/]

\section{doi:10.1186/1741-7007-12-5}

Cite this article as: Hemer et al:: Host insulin stimulates Echinococcus multilocularis insulin signalling pathways and larval development. BMC Biology 2014 12:5.

\section{Submit your next manuscript to BioMed Central and take full advantage of:}

- Convenient online submission

- Thorough peer review

- No space constraints or color figure charges

- Immediate publication on acceptance

- Inclusion in PubMed, CAS, Scopus and Google Scholar

- Research which is freely available for redistribution 